\title{
Xist spatially amplifies SHARP recruitment to balance chromosome-wide silencing and specificity to the $\mathrm{X}$ chromosome
}

Joanna W. Jachowicz ${ }^{1 *}$, Mackenzie Strehle ${ }^{1 *}$, Abhik K. Banerjee1,2, Jasmine Thai1, Mario R. Blanco ${ }^{1}$, and Mitchell Guttman'1†

\begin{abstract}
Although thousands of IncRNAs are encoded in mammalian genomes, their mechanisms of action are largely uncharacterized because they are often expressed at significantly lower levels than their proposed targets. One such IncRNA is Xist, which mediates chromosome-wide gene silencing on one of the two $X$ chromosomes to achieve gene expression balance between males and females. How a limited number of Xist molecules can mediate robust silencing of a significantly larger number of target genes ( 1 Xist RNA: 10 gene targets) while maintaining specificity to genes on the $X$ within each cell is unknown. Here, we show that Xist drives non-stoichiometric recruitment of the essential silencing protein SHARP (also called Spen) to amplify its abundance across the inactive $X$, including at regions not directly occupied by Xist. This amplification is achieved through concentration-dependent homotypic assemblies of SHARP on the $X$ and is required for chromosome-wide silencing. We find that expressing Xist at higher levels leads to increased localization at autosomal regions, demonstrating that low levels of Xist are critical for ensuring its specificity to the $X$ chromosome. We show that Xist (through SHARP) acts to suppress production of its own RNA which may act to constrain overall RNA levels and restrict its ability to spread beyond the $X$. Together, our results demonstrate a spatial amplification mechanism that allows Xist to achieve two essential but countervailing regulatory objectives: chromosome-wide gene silencing and specificity to the $X$. Our results suggest that this spatial amplification mechanism may be a more general mechanism by which other low abundance IncRNAs can balance specificity to, and robust control of, their regulatory targets.
\end{abstract}

\section{INTRODUCTION}

In recent years, thousands of IncRNAs have been identified and many have been proposed to regulate gene expression [1-5]. However, their precise mechanisms of action remain largely uncharacterized. One of the key issues is that IncRNAs are generally expressed at low levels such that the number of RNA molecules is less than the number of targets that they are proposed to regulate (sub-stoichiometric) [6-8]. How an individual IncRNA molecule can control multiple distinct targets when it cannot engage with all of them simultaneously remains unknown and has led some to suggest that these lowly expressed IncRNAs may not be functionally important $[9,10]$.
One example of a IncRNA that is expressed at sub-stoichiometric levels relative to its targets is Xist. Expression of Xist is sufficient to induce transcriptional silencing of more than a thousand genes across the $>167$ million bases of DNA on the $X$ chromosome in order to achieve dosage balance of expression between males and females [11-17]. Previous studies have shown that there are $\sim 60-200$ Xist molecules within an individual cell [18-20], corresponding to an average of $\sim 1$ Xist RNA for every $\sim 10$ genes encoded on the X.

Xist represents an ideal system in which to explore how sub-stoichiometric levels of a IncRNA can regulate its more abundant targets because it is functionally important (developmentally essential) [11,21] with a

\footnotetext{
1 Division of Biology and Biological Engineering, California Institute of Technology, Pasadena, CA 91125, USA 2 Keck School of Medicine, University of Southern California, Los Angeles, CA 90089, USA

* Co-first authors † Email: mguttman@caltech.edu
} 
clear phenotype (transcriptional silencing) [22-24] that occurs at precise and well-defined regulatory targets (X chromosome genes) [15-17]. Recent studies have begun to elucidate the mechanisms by which Xist localizes across the $X$ chromosome and recruits silencing proteins to initiate chromosomewide silencing. Rather than binding to precise DNA sequences, Xist diffuses from its transcription locus to DNA sites that are in close 3D proximity at both genic and intergenic regions $[16,17]$. Xist binds directly to SHARP (also called SPEN) [22,25-28], an RNA binding protein that associates with the SMRT and HDAC3 repressive complex to deacetylate histones [29-31], evict RNA Polymerase II [22,24,32], and silence transcription on the $X[22,24,25,32-34]$.

Although these discoveries have uncovered several long-sought molecular mechanisms underlying Xistmediated silencing, they raise critical new questions about how Xist can achieve the essential quantitative features required for dosage balance. Specifically, Xistmediated silencing needs to be both specific to ensure that only genes on the $X$ (but not autosomes) are silenced, and robust to ensure that each of the several hundred distinct genes across the $\mathrm{X}$ are silenced within each individual cell.

Current models, based on ensemble measurements, cannot explain how Xist achieves these two regulatory objectives - specificity to the $X$ and chromosomewide silencing - within single cells. For example, Xist localization based on 3D proximity could explain its preferential localization on the $X$; however, as the $X$ is not partitioned from other chromosomes, this mechanism would not preclude Xist spreading to some autosomal regions within individual cells. Because Xist can silence transcription of genes on autosomes when present in proximity [35-37], its specificity to the $X$ is essential to preclude gene silencing of autosomal genes. Moreover, while Xist localizes broadly across the X when measured in a population of cells $[16,17]$, it cannot localize at all of these positions simultaneously because there is only $\sim 1$ Xist RNA molecule for each megabase of genomic DNA within an individual cell (see Supplemental Note). Accordingly, Xist must localize heterogeneously at distinct locations within individual cells. Such heterogeneous localization would be expected to lead to heterogenous silencing where different genes are silenced in distinct cells. Yet, $\mathrm{X}$ chromosome silencing is not heterogenous (see Supplemental Note) [24,38]. Therefore, the stoichiometric silencing model whereby the Xist-SHARP complex localizes at each gene to silence transcription cannot explain how chromosomewide silencing occurs within single cells.

Here, we explore the mechanisms of how the Xist IncRNA can achieve chromosome-wide gene silencing while ensuring specificity to the $X$ within each individual cell during initiation of $\mathrm{XCl}$.

\section{RESULTS}

\section{SHARP enrichment on the $\mathrm{Xi}$ increases in a non-stoichiometric manner relative to Xist}

To explore how sub-stoichiometric levels of Xist can silence genes across the $\mathrm{X}$, we analyzed the temporal and quantitative relationship between localization of Xist and the essential silencing protein SHARP on the inactive $X(X i)$. SHARP binds directly to $X i s t$ and its enrichment on the $X i$ is dependent on Xist $[20,22,24-$ 27]. We reasoned that if SHARP is recruited to the $X i$ solely through its ability to directly bind to Xist, then the concentration of SHARP would increase proportionally to the concentration of Xist across time (stoichiometric recruitment). In this case, the rate of Xist and SHARP accumulation on the $X$ would be proportional to each other and their ratio would be constant across time (Fig. 1A).

To measure this, we used a female $\mathrm{F} 1$ hybrid (BI6 $x$ Cast) mouse embryonic stem cell (mESC) line containing a doxycycline (dox) inducible Xist gene at its endogenous locus and an in-frame HALO tag inserted into both copies of the endogenous SHARP protein (TX-SHARP-HALO cells) [24,39]. This system allows for more temporally synchronized expression of Xist compared to differentiation of female mESCs (Fig. S1A), achieves robust chromosome-wide silencing by 72 hours of induction (Fig. S1B), and utilizes the same molecular components required for initiation of $\mathrm{XCl}$ during development and differentiation [23,40]. We induced Xist expression and visualized SHARP (using either a dye that conjugates directly to HALO or an antibody against the HALO tag) along with Xist (using RNA-FISH) across five timepoints (1-48 hours) following dox induction (Fig. 1B; Fig. S1C, S1D). Using both SHARP visualization approaches, we found that the area of the Xist-coated territory increased (Fig. $1 \mathrm{C})$ whereas the total intensity of Xist over the territory increased initially, plateaued, and remained relatively constant (Fig. S1E). This means that the average Xist intensity within the territory decreased over time (Fig. $1 \mathrm{C})$. In contrast, the average intensity of SHARP within the territory continued to increase across all timepoints (Fig. 1C; Fig. S1F; see Methods for quantification). Thus, the ratio of SHARP to Xist intensity is not constant across time, but instead increases in a non-linear manner (Fig. 1D; see Fig.1A for comparison).

To ensure that this effect is not simply a product of our synthetic dox-inducible system (Fig. S1A), we measured the localization of Xist and SHARP across time in female mESCs upon endogenous initiation of XCl using retinoic acid (RA)-induced differentiation. We imaged Xist and SHARP after 2 and 3 days of differentiation (Fig. S1G) and observed a similar relationship between the levels of Xist and the levels of SHARP across time 
bioRxiv preprint doi: https://doi.org/10.1101/2021.10.27.466149; this version posted October 28, 2021. The copyright holder for this preprint (which was not certified by peer review) is the author/funder, who has granted bioRxiv a license to display the preprint in perpetuity. It is made available under aCC-BY-NC-ND 4.0 International license.

A
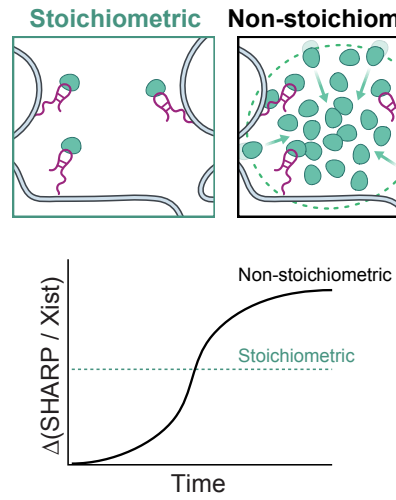

C
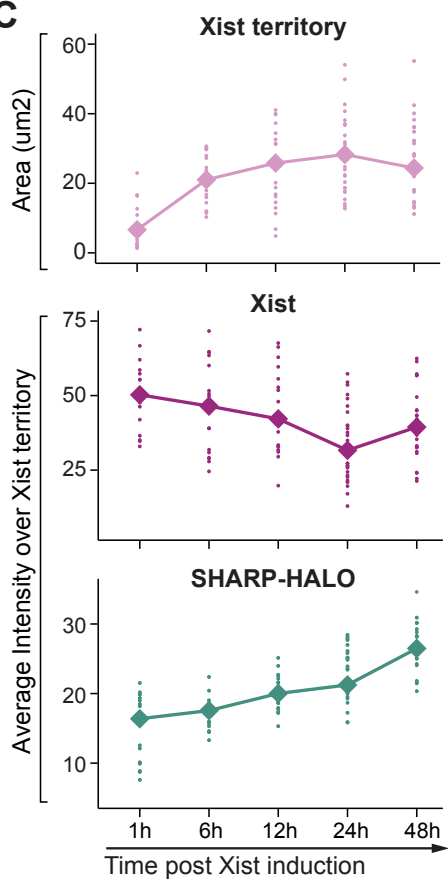

B

Non-stoichiometric

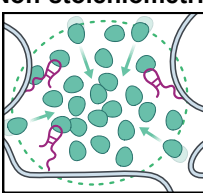

SHARP

(Halo)

Merge

D
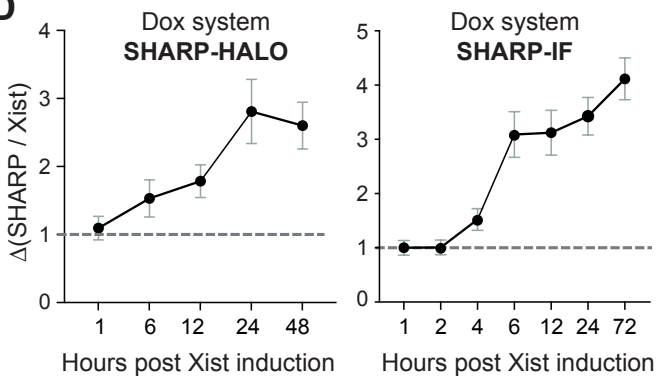

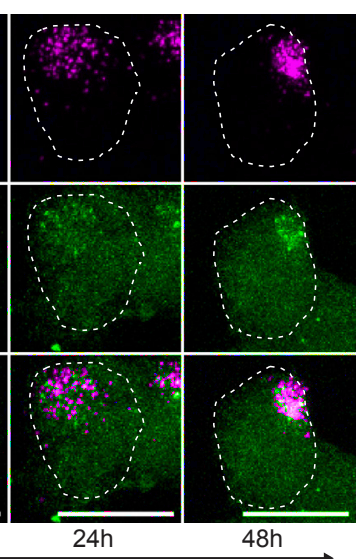

E

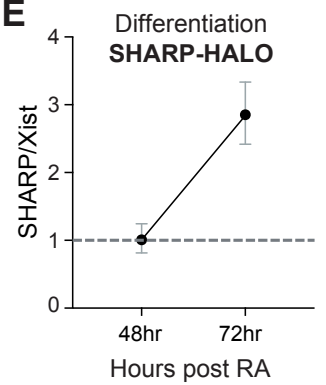

$\mathbf{F}$

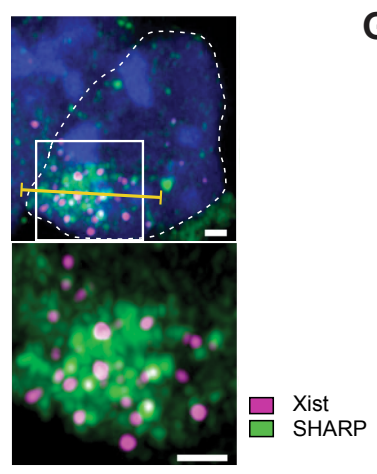

G

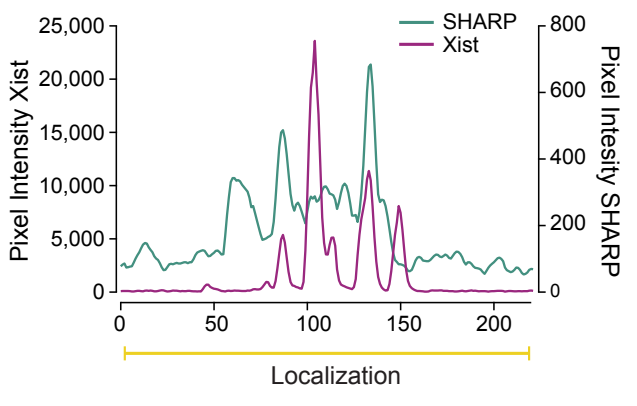

Figure 1. SHARP enrichment over the Xi increases in a non-stoichiometric manner relative to Xist.

(A) Schematic of two alternative models of Xist-dependent SHARP recruitment to the Xi. Left: stoichiometric, where SHARP (green) localizes through a direct interaction with Xist (magenta); Right: non-stoichiometric, where SHARP can localize even when not directly associated with Xist. Bottom: In the stoichiometric model, the ratio of SHARP to Xist is directly proportional and constant across time; in the non-stoichiometric model, the ratio of SHARP to Xist increases over time in a non-linear manner. (B) Representative images of Xist and SHARP localization in TX-SHARP-HALO female mESCs across 48 hours of Xist expression; Xist visualized by RNA-FISH (magenta), SHARP visualized by direct labeling of endogenous SHARP-Halo with Halo ligand (green). Images shown as max. projections; scale bars $10 \mu \mathrm{m}$. (C) Quantification of temporal dynamics across individual cells (Fig. 1B). Top panel: area of the territory coated by Xist RNA ( $\mu$ m2); Middle panel: average fluorescent intensity of Xist (RNA-FISH) over a unit of Xist territory; Bottom panel: average fluorescent intensity of SHARP (direct Halo labeling) over a unit of Xist territory. Dots represent measurement per individual cell, squares represent mean value for each timepoint. (D) Ratio of SHARP to Xist average intensities in TX-SHARP-HALO mESCs at timepoints after Xist induction normalized to one hour group. Left panel: SHARP visualized by direct Halo labeling of endogenous SHARP-Halo across 48 hours; Right panel: SHARP visualized by anti-Halo immunofluorescence of endogenous SHARP-Halo across 72 hours. Dots represent mean per each timepoint, whiskers represent standard deviation. (E) Ratio of SHARP (direct Halo labeling) to Xist (RNA-FISH) average intensities upon retinoic acid induced differentiation of TX-SHARP-HALO mESCs normalized to 48 hours group. Dots represent mean per each timepoint, whiskers represent standard deviation. (F) Super-resolution imaging of Xist (RNA-FISH; magenta) and endogenous SHARP-Halo (direct Halo labeling; green) in TX-SHARP-HALO mESCs after 24 hours of Xist induction using an Airyscan detector. Top: a single nucleus; Bottom: zoom-in on Xist territory from the top image demarcated by the white box. Images shown as max. projections; scale bars $1 \mu \mathrm{m}$. Yellow line shows where the intensity profile (Fig. $1 \mathrm{G}$ ) was measured. (G) Line intensity profile from image in Fig. 1F showing Xist and SHARP intensities across the Xist territory.

- SHARP levels increased at a faster rate than those of Xist between the two timepoints (Fig. 1E; Fig. S1H). These results demonstrate that SHARP recruitment to the $X$ occurs in a non-stoichiometric manner relative to Xist.

Based on this, we explored whether SHARP is enriched at regions within the Xist-coated territory that are not bound by Xist. To do this, we focused on the Xist territory after 24 hours of dox induction and performed super-resolution imaging of Xist and SHARP (Fig. 1F). We observed foci of Xist within the territory, whereas SHARP exhibits enrichment across the entire territory. As such, there are clear regions of high concentration of SHARP even where Xist is not present (Fig. 1G). 


\section{SHARP forms concentration-dependent assemblies in the nucleus}

We next explored how non-stoichiometric recruitment of SHARP to the $X$ might occur. SHARP is an $\sim 450$ kilodalton protein containing four RRM domains $[41,42]$ that bind to Xist $[26,32]$ and a SPOC domain that is critical for recruiting the SMRT and HDAC3 proteins $[24,30,31]$. The remainder of SHARP is predicted to consist of long intrinsically disordered regions (IDRs; Fig. 2A). Recently, many proteins containing long IDRs have been shown to form concentration-dependent assemblies through multivalent, high-avidity associations [43-46]. Based on this observation, we hypothesized that SHARP might similarly form such concentration-dependent assemblies (Fig. 2B). (Although some concentration-dependent assemblies have been shown to form through phase separation, this is not the only mechanism by which they form $[47,48]$. In this specific context we are testing whether SHARP forms concentration-dependent assemblies rather than the precise biophysical characteristics of its formation.)

To test this hypothesis, we explored whether SHARP exhibits three known features of multivalent, high-avidity assemblies [43-46]. Specifically, we asked (i) does SHARP form high-concentration foci in the nucleus, (ii) is formation of these foci dependent on the overall concentration of SHARP, (iii) are these foci dependent on multivalent associations mediated through the IDRs, and (iv) are these foci dependent on associations with other molecules of SHARP (homotypic assemblies)?

We expressed full-length SHARP tagged with monomeric eGFP (FL-SHARP; Fig. S2A) in HEK293T cells, a cell type that allows for efficient transfection and controlled expression of the large plasmid containing SHARP and enables characterization of its biochemical and biophysical properties independently of its functional targets. Using this system, we performed live cell imaging and observed that FL-SHARP molecules formed discrete foci within the nucleus (Fig. 2C; Movie S1). These SHARP assemblies also displayed other features of multivalent, IDR-mediated assemblies in that individual molecules exchanged rapidly within a SHARP focus (Fig. S2B) and SHARP foci merged together into larger structures (fusion) or split apart into smaller structures (fission) across time [49,50] (Movie S2; Fig. S2C, S2D).

Next, we used the dox-inducible promoter that drives FL-SHARP expression to titrate its level across a $>1,000$-fold range of concentrations and determine whether formation of these foci depends on total protein concentration per cell.

We observed that SHARP formed foci only when present at higher concentrations; at low concentrations
SHARP was diffuse throughout the nucleus (Fig. 2D, 2E; Fig. S2E; see Methods for quantification) similar to other proteins that do not form assemblies (Fig. S2F).

To determine whether formation of SHARP assemblies is dependent on multivalent interactions driven by its IDRs, we expressed eGFP-tagged SHARP lacking its IDRs (IIDR-SHARP; Fig. S2A) in HEK293T cells and imaged its behavior. In contrast to the full-length protein, $\triangle I D R-S H A R P$ did not form foci (Fig. 2F). Instead, $\triangle$ IDR-SHARP localized diffusively throughout the nucleus, even when present at the concentration where FL-SHARP formed foci (Fig. 2G).

Finally, we explored whether these IDR-dependent assemblies form through multivalent associations with other molecules of SHARP (homotypic assemblies) or require sequence-specific associations with other proteins (heterotypic assemblies). To do this, we fused $\triangle I D R-S H A R P$ to an mCherry-tagged version of the IDR of FUS, an RNA binding protein that is known to form multivalent homotypic associations both in vitro and in vivo [51-53] (FUS- $\triangle$ IDR-SHARP; Fig. S2A) and tested if this synthetic protein rescues the ability of SHARP to form foci independently of its IDRs. We observed that FUS-AIDR-SHARP forms assemblies in the nucleus that are comparable to those observed for FL-SHARP (Fig. 2H). While we do not exclude the possibility that the IDRs of SHARP may form heterotypic associations with other molecules, these results indicate that homotypic associations are essential for SHARP to form the observed assemblies.

Together, these results indicate that SHARP forms concentration-dependent assemblies in the nucleus and that formation of these assemblies is dependent on homotypic multivalent interactions driven by its IDRs (Fig. 2l).

\section{SHARP recruitment to the $X i$ is dependent on IDR-mediated homotypic associations}

To determine if IDR-dependent assemblies of SHARP are critical for its enrichment on the $\mathrm{Xi}$, we tested whether deletion of the IDRs impacts localization over the $\mathrm{X}$.

To do this, we first generated a mESC line containing a deletion of both copies of the endogenous SHARP gene (SHARP-KO; Fig. S3A). In parallel, we utilized mESCs containing an auxin-degradable SHARP (SHARP-AID) [24]. Within each of these lines (SHARP-KO and SHARP-AID), we stably expressed a HALO-tagged or eGFP-tagged version of either full length SHARP (FL-SHARP), SHARP containing a deletion of its RRM domains ( $\triangle$ RRM-SHARP), or SHARP containing a deletion of its IDRs ( $\triangle I D R-S H A R P)$ (Fig. S3B, S3C). We visualized each of these tagged SHARP proteins along with Ezh2 (to demarcate the Xi) after Xist expression for 
bioRxiv preprint doi: https://doi.org/10.1101/2021.10.27.466149; this version posted October 28, 2021. The copyright holder for this preprint (which was not certified by peer review) is the author/funder, who has granted bioRxiv a license to display the preprint in perpetuity. It is made available under aCC-BY-NC-ND 4.0 International license.

A

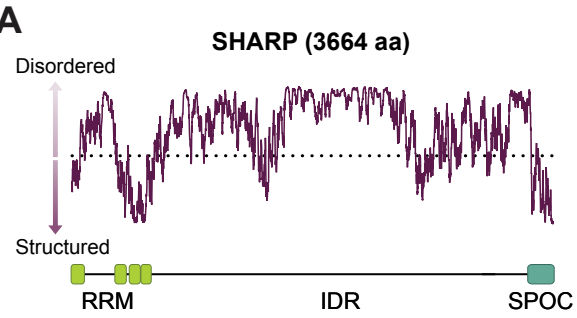

B

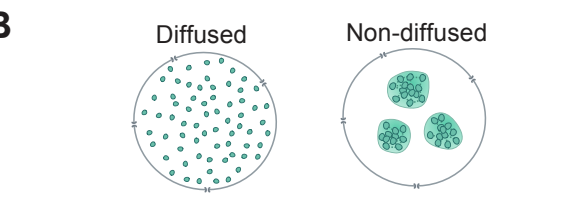

D

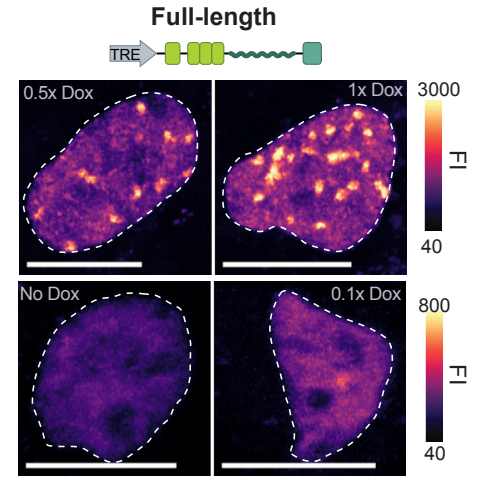

$\mathbf{F}$

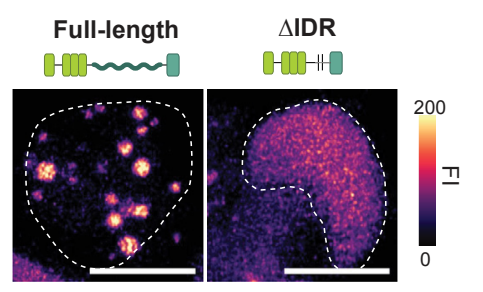

H

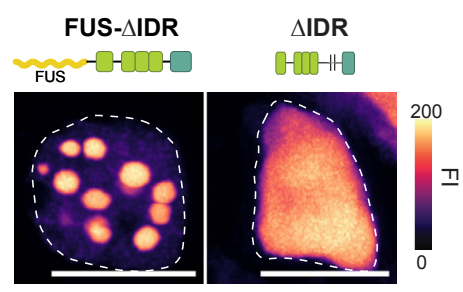

C
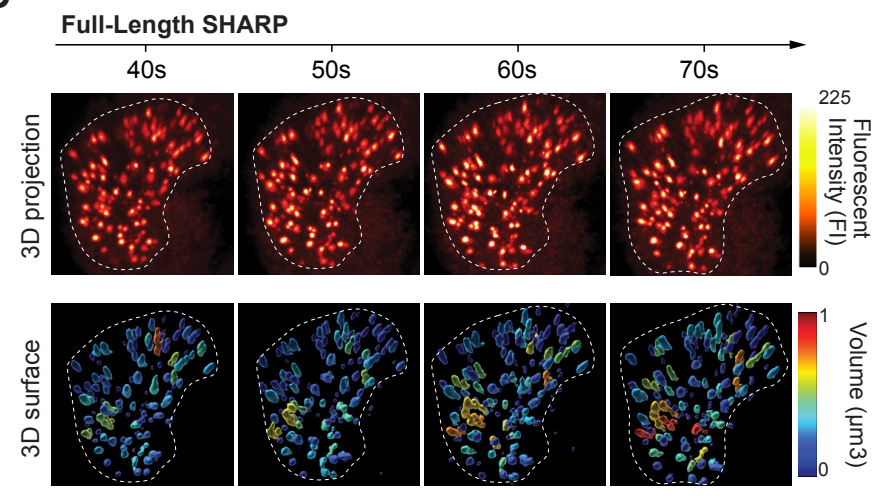

$\mathbf{E}$

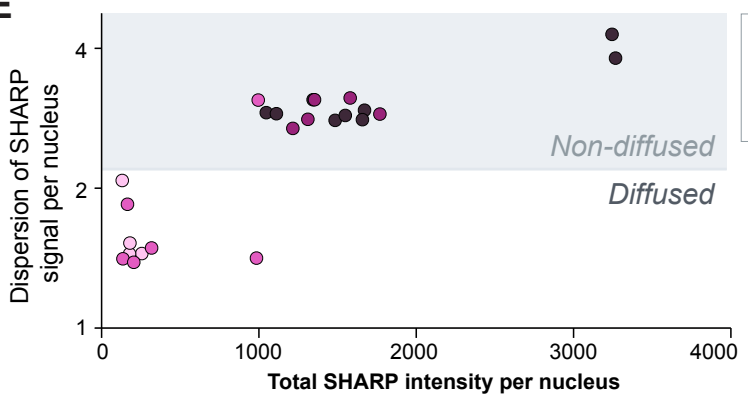

No Dox

$0.1 \times$ Dox

$0.5 x$ Dox

1x Dox

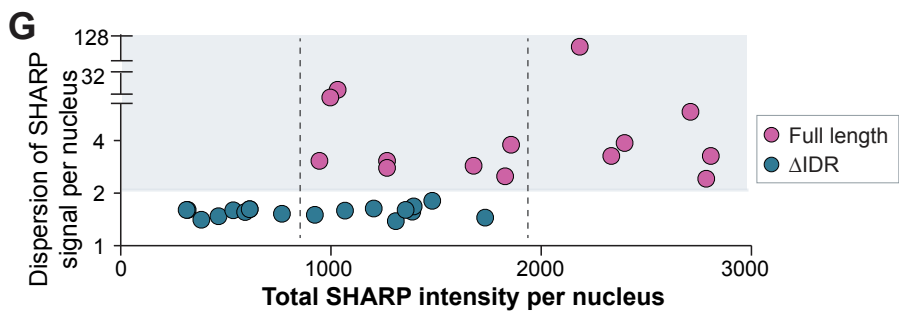

I

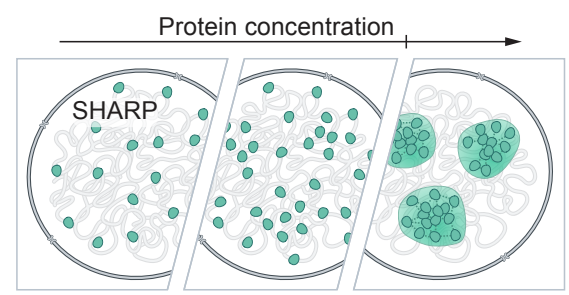

Figure 2: SHARP forms multivalent concentration-dependent assemblies in the nucleus

(A) Disordered scores across the SHARP protein using IUPred2 software predictions. Dotted line represents 0.5 probability value for a given structure to be ordered. Bottom visualization demarcates position of known SHARP domains - RNA Recognition motif (RRM; bright green), Spen Paralog and Ortholog C-terminal (SPOC, dark green). (B) Schematic representation of molecules within a nucleus organized in a diffused or non-diffused (focal) manner. (C) Images across four time-points from a live-cell movie of eGFP-tagged FL-SHARP in transiently transfected HEK293T cells showing non-diffused, focal organization of SHARP molecules. Top panel: 3D reconstructions of the fluorescent intensity signal; Bottom panel: 3D volume reconstructions color-coded based on the size of the condensate; Fluorescent Intensity (FI) (D) Images representing localization patterns of eGFP-tagged FL-SHARP in transiently transfected HEK293T cells across increasing expression levels of SHARP (SHARP under dox inducible promoter; dox $1 \mathrm{x}=2 \mu \mathrm{g} / \mathrm{mL}$ ). Images shown as max. projections; scale bars $10 \mu \mathrm{m}$; Fluorescent Intensity (FI). (E) Quantification of images (Fig. 1D) plotting the dispersion of SHARP signal across the nucleus versus average SHARP fluorescent intensity per nucleus. (F) Representative images of FL-SHARP and $\triangle I D R-S H A R P$ localization patterns in transiently transfected HEK293T cells. Images shown as max. projections; scale bars $10 \mu \mathrm{m}$; Fluorescent Intensity (FI). (G) Quantification of images (Fig. 1F) plotting the dispersion of SHARP signal across the nucleus versus average SHARP fluorescent intensity per nucleus. Dashed line represents range of fluorescent intensity that is similar for both groups. (H) Images representing localization patterns of mCherry-tagged FUS-AIDR-SHARP and eGFP-tagged $\triangle I D R$-SHARP in transiently transfected HEK293T cells. Images shown as max. projections; scale bars 10 $\mu \mathrm{m}$; Fluorescent Intensity (FI). (I) Schematic depicting formation of concentration-dependent SHARP assemblies.

$>72$ hours (Fig. 3A; Fig. S3D). As expected, FL-SHARP was enriched over the Xi compartment. In contrast, $\triangle R R M-S H A R P$ failed to localize on the Xi. Interestingly, we also observed a strong decrease in the enrichment of $\triangle I D R-S H A R P$ over the $\mathrm{Xi}$, comparable to that observed upon deletion of the RRM domains (Fig. 3B; see Fig. S3E for quantification schematics). The level of Ezh2 was similar in all conditions (Fig. 3B). 
bioRxiv preprint doi: https://doi.org/10.1101/2021.10.27.466149; this version posted October 28, 2021. The copyright holder for this preprint (which was not certified by peer review) is the author/funder, who has granted bioRxiv a license to display the preprint in perpetuity. It is made available under aCC-BY-NC-ND 4.0 International license.

Because SHARP binds directly to Xist [22,25-27], we tested whether the $\triangle R R M$ - and $\triangle I D R-S H A R P$ mutants fail to localize on the Xi simply because they cannot bind Xist. To test this, we UV-crosslinked intact cells to form a covalent crosslink between directly interacting proteins and RNA, purified the HALO-tagged SHARP proteins using fully denaturing conditions, and sequenced the associated RNAs (see Methods). We observed that FL-SHARP forms a highly specific interaction with the A-repeat region of Xist. In contrast, expression of $\triangle R R M-S H A R P$ ablated this interaction across Xist. Interestingly, $\triangle I D R-S H A R P$ is still able to bind the A-repeat of Xist at comparable levels and positions to that observed for FL-SHARP and the endogenous SHARP protein (Fig. 3C, 3D). These observations are consistent with previous studies that showed that the
RRM domains of SHARP are sufficient to bind to Xist $[26,32]$. Together, these results demonstrate that the IDRs of SHARP are essential for its enrichment on the Xi (Fig. 3A, 3B) even though they are not required for direct binding to Xist (Fig. 3C, 3D).

To exclude the possibility that $\triangle I D R-S H A R P$ impacts localization on the $\mathrm{Xi}$ because it disrupts a cryptic localization domain contained within the protein, we tested whether we could rescue the Xi localization deficits simply by promoting multivalent homotypic associations. To do this, we used our FUS- $\triangle$ IDRSHARP system that forms foci independently of its IDRs (Fig. 2H) and explored whether this could rescue SHARP localization on the $X$. Indeed, we observed that FUS- $\triangle$ IDR-SHARP showed levels of localization over the $\mathrm{Xi}$ that were comparable to FL-SHARP
A

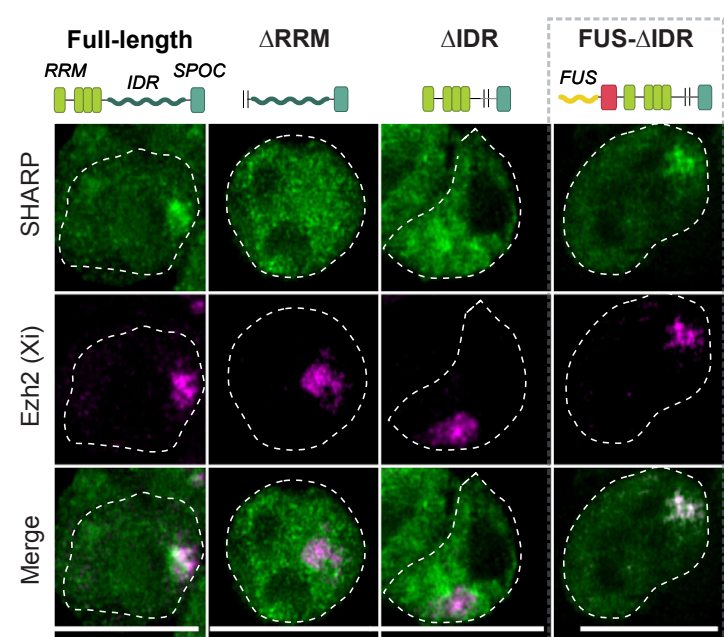

B

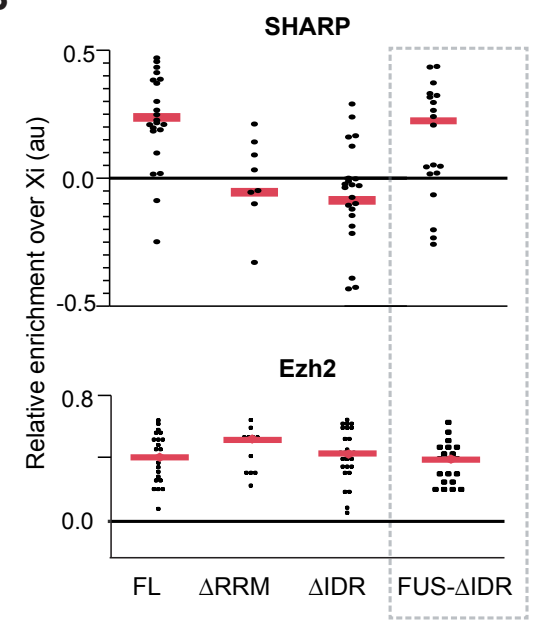

C

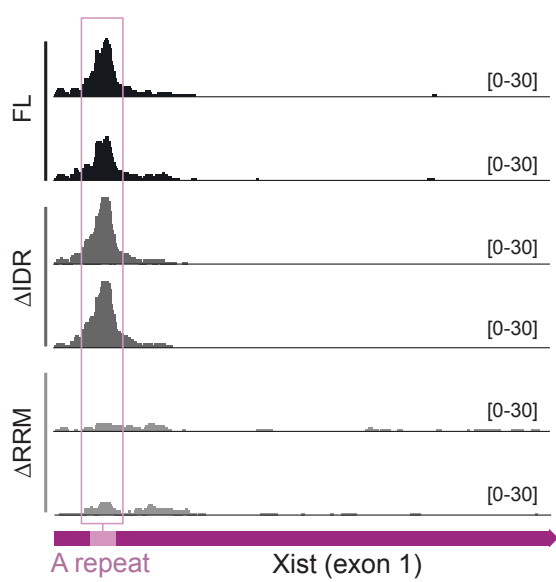

D

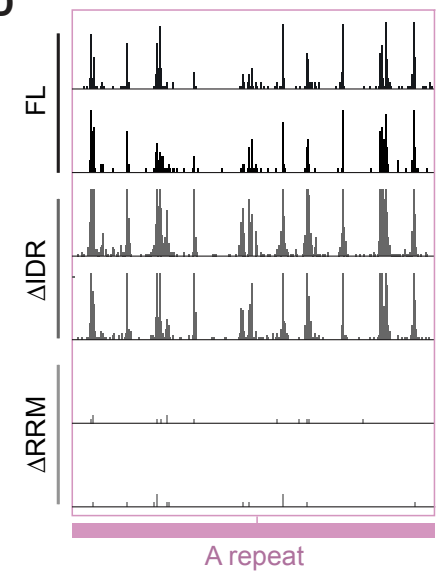

Figure 3: Formation of SHARP assemblies are required for its enrichment on the Xi and dispensable for Xist binding (A) Representative images of SHARP enrichment (eGFP, green) over the Xi (anti-Ezh2 immunofluorescence, magenta) in TX SHARP-KO mESCs containing

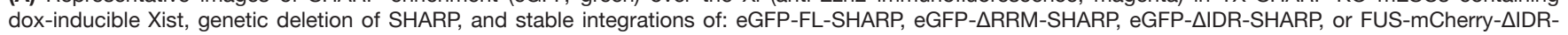
SHARP constructs (see Fig. S3B-C for cell lines details). Xist induction for $72 \mathrm{~h}$, images shown as z-sections; scale bars show $10 \mu \mathrm{m}$. (B) Quantification of images (Fig. 3A) plotting (top panel) SHARP fluorescent intensity over the Xi (denoted by Ezh2) normalized to the fluorescent intensity of a random nuclear region of the same size or (bottom panel) Ezh2 fluorescent intensity over the same area normalized to random nuclear region (see Fig. S3D for quantification details). Values for individual nuclei $(n>10)$ are shown; red lines represent median values; 0 represents enrichment not higher than measured over a random nuclear region. (C) SHARP enrichment across the first exon of Xist after UV-crosslinking and purification using the HALO tag in female TX SHARP-AID mESCs treated with auxin. Halo-tags were fused to FL-SHARP (top), $\triangle I D R-S H A R P$ (middle), or $\triangle$ RRM-SHARP (bottom, see Fig. S3B-C for cell line details). Two replicates are shown for each cell line; magenta square represents beginning of the first Xist exon, pink square demarcates A-repeat (SHARP binding site). (D) Crosslink-induced truncation sites are shown for a zoom-in on the A-repeat region from Fig. 3C demarcated by pink square across three conditions. 
after 72 hours of Xist induction (Fig. 3A, 3B). These results demonstrate that the ability of SHARP to form homotypic assemblies (via its IDRs) is essential for its accumulation on the $\mathrm{Xi}$.

\section{Formation of SHARP assemblies is required for chromosome-wide gene silencing}

Because the $\triangle$ IDR-SHARP mutant does not accumulate on the $\mathrm{Xi}$, we hypothesized that the ability to form SHARP assemblies is required for Xist-mediated transcriptional silencing during initiation of $\mathrm{XCl}$.

To measure silencing, we performed RNA FISH on Xist and the introns of (i) several genes located across the $X$ that are known to be silenced upon $\mathrm{XCl}$ and (ii) genes that are known to escape $\mathrm{XCl}$ and therefore remain active upon Xist induction (Fig. 4A; Fig. S4A, Supplemental Note). This single cell readout allows us to restrict our analyses to cells that induce Xist expression ( 50\% of cells) and retain both $X$ chromosomes ( $50 \%$ of cells; Fig. S4B) $[39,54,55]$. Of these cells, we found that $\sim 80 \%$ successfully silenced gene expression on one of the two $X$ chromosomes upon Xist induction in wild-type mESCs (Fig. 4B, 4C; Fig. S4C). Next, we measured gene silencing upon genetic deletion (SHARP-KO) or auxin-mediated degradation (SHARP-AID) of SHARP and found that both conditions lead to loss of Xistmediated transcriptional silencing (Fig. 4B, 4C; Fig. S4C).

We measured transcription of the same $X$-linked genes after stable expression of FL-SHARP, $\triangle$ RRM-SHARP, or $\triangle I D R-S H A R P$ in both SHARP-KO and SHARP-AID backgrounds (Fig. 4D, 4F; Fig. S4D, S4F). As expected, expression of FL-SHARP rescued silencing of these X-linked genes. In contrast, expression of $\triangle$ RRM-SHARP failed to silence any of these X-linked genes, consistent with the fact that it can no longer bind to Xist. Importantly, expression of $\triangle I D R-S H A R P$ also failed to silence these genes (Fig. 4E, 4G; Fig. S4E, S4G). To confirm that silencing depends on the ability of SHARP to form assemblies via its IDRs and not on a specific sequence within the IDRs, we performed the same assay using our SHARP-KO or SHARP-AID cells expressing the synthetic FUS- $\triangle$ IDR-SHARP construct that rescues SHARP assembly formation and $\mathrm{Xi}$ enrichment (Fig. 2H; Fig. 3A, 3B). We observed a rescue of Xist-mediated transcriptional silencing, comparable to that observed upon expression of FL-SHARP ( 70\% silenced cells for FUS- $\triangle$ IDR-SHARP versus $~ 75 \%$ for FL-SHARP) (Fig. 4E, 4G; Fig. S4E, S4G).

Together, these results demonstrate that direct binding of SHARP to Xist (via its RRM domains) and its ability to form concentration-dependent homotypic assemblies (via its IDRs) are both essential and distinct components required for chromosome-wide silencing on the Xi. Our data suggest a spatial amplification mechanism where the direct interaction between Xist (which is enriched on the $X$ chromosome) and SHARP (which is diffusible throughout the nucleus) acts to increase the local concentration of SHARP on the $X$ chromosome. The resulting high local concentrations of SHARP on the $X$ enable formation of IDR-mediated concentration-dependent assemblies that can occur between molecules that are not directly bound to Xist. In this way, these RNA-mediated assemblies can lead to the accumulation of SHARP on the $X i$ in stoichiometric excess of the number of Xist molecules to enable chromosome-wide silencing (Fig. 4H).

\section{Xist expression levels are critical for controlling spreading to autosomes}

This spatial amplification mechanism explains how Xist can achieve chromosome-wide silencing despite being expressed at sub-stoichiometric levels relative to its target genes (Fig. S5A, S5B, S5C). However, it does not explain why Xist expression levels are low and whether this might be critical for its functional role during $\mathrm{XCl}$. Because Xist spreads to sites on the $X$ based on 3D diffusion from its transcription locus $[16,17]$, we hypothesized that its expression level might control how far it spreads in the nucleus. If true, we would expect that expressing Xist at increasing concentrations would lead to increasing localization of Xist to autosomal regions.

To test this, we used our dox-inducible Xist system, which enables induction of Xist across a range of expression levels by titrating the concentration of dox (Fig. 5A). We induced Xist expression across a range of dox concentrations (referred to as a $0.05 x-3 x$ Dox, where $1 \mathrm{x}=2 \mu \mathrm{g} / \mathrm{mL}$ ), imaged Xist localization in individual cells (Fig. 5B) and observed a strong correlation between Xist expression levels and the area of the nucleus it occupies within individual cells $(r=0.75$; Fig. $5 \mathrm{C})$. Specifically, Xist occupies on average $\sim 6.5 \%$ of the area of the nucleus when expressed upon RA-induced differentiation (endogenous control). However, cells treated with $3 x$ dox express on average 3.4-fold higher levels of Xist (relative to average endogenous levels) and Xist occupies on average $\sim 23 \%$ of the area of the entire nucleus (Fig. 5C).

To determine whether the larger nuclear volumes occupied by Xist correspond to increased localization on autosomes, we performed RNA Antisense Purification (RAP) [16] on Xist and sequenced its associated DNA regions across three different induction conditions $(0.25 x, 1 x$, and $3 x$ dox) as well as a negative (no dox) control (Fig. 5D). Because RAP is a bulk measurement, we first confirmed that Xist expression increases in the presence of increasing dox concentrations within a 
bioRxiv preprint doi: https://doi.org/10.1101/2021.10.27.466149; this version posted October 28, 2021. The copyright holder for this preprint (which was not certified by peer review) is the author/funder, who has granted bioRxiv a license to display the preprint in perpetuity. It is made available under aCC-BY-NC-ND 4.0 International license.

A
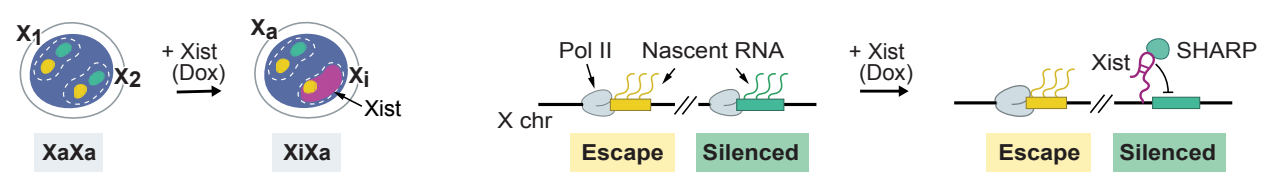

B
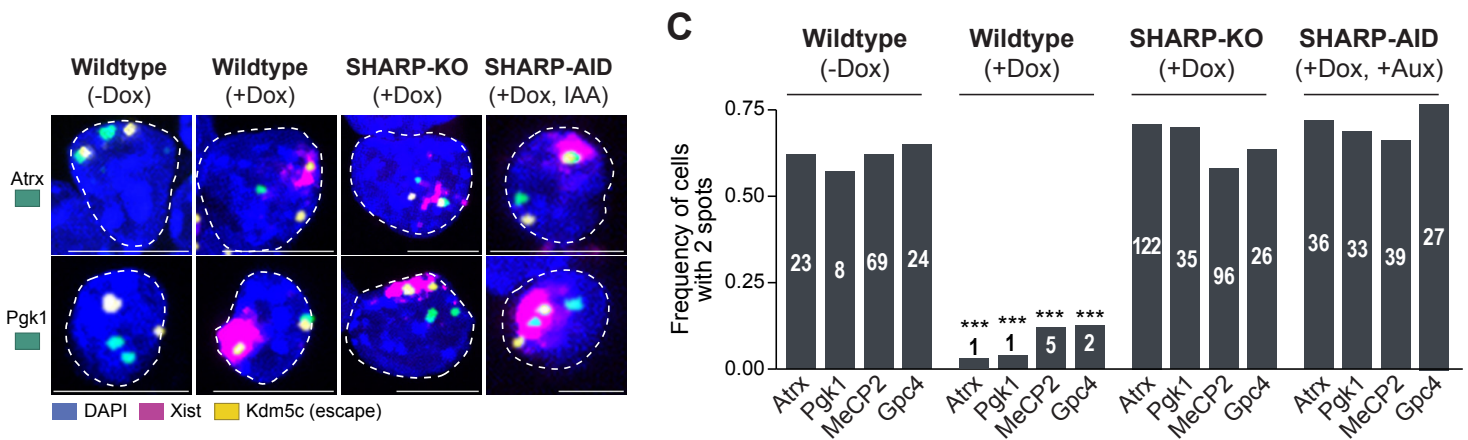

D

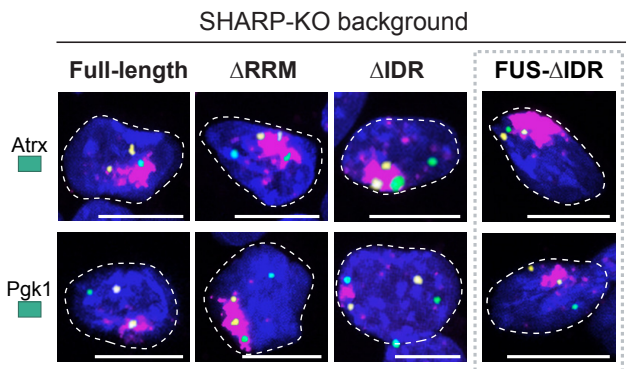

$\square$ DAPI $\square$ Xist $\square$ Kdm5c (escape)

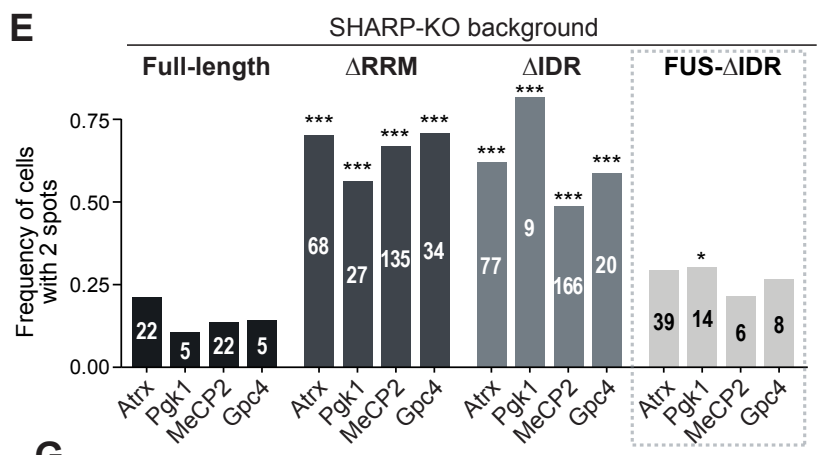

$\mathbf{F}$

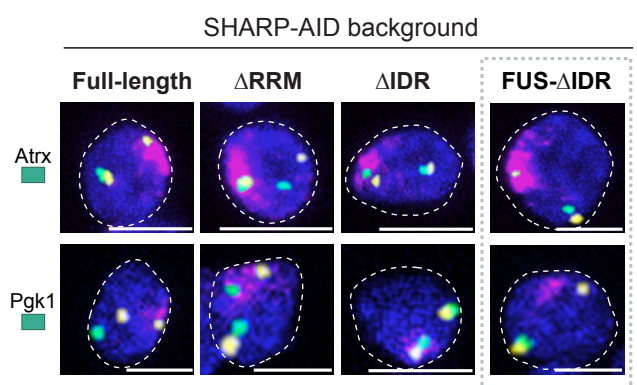

G
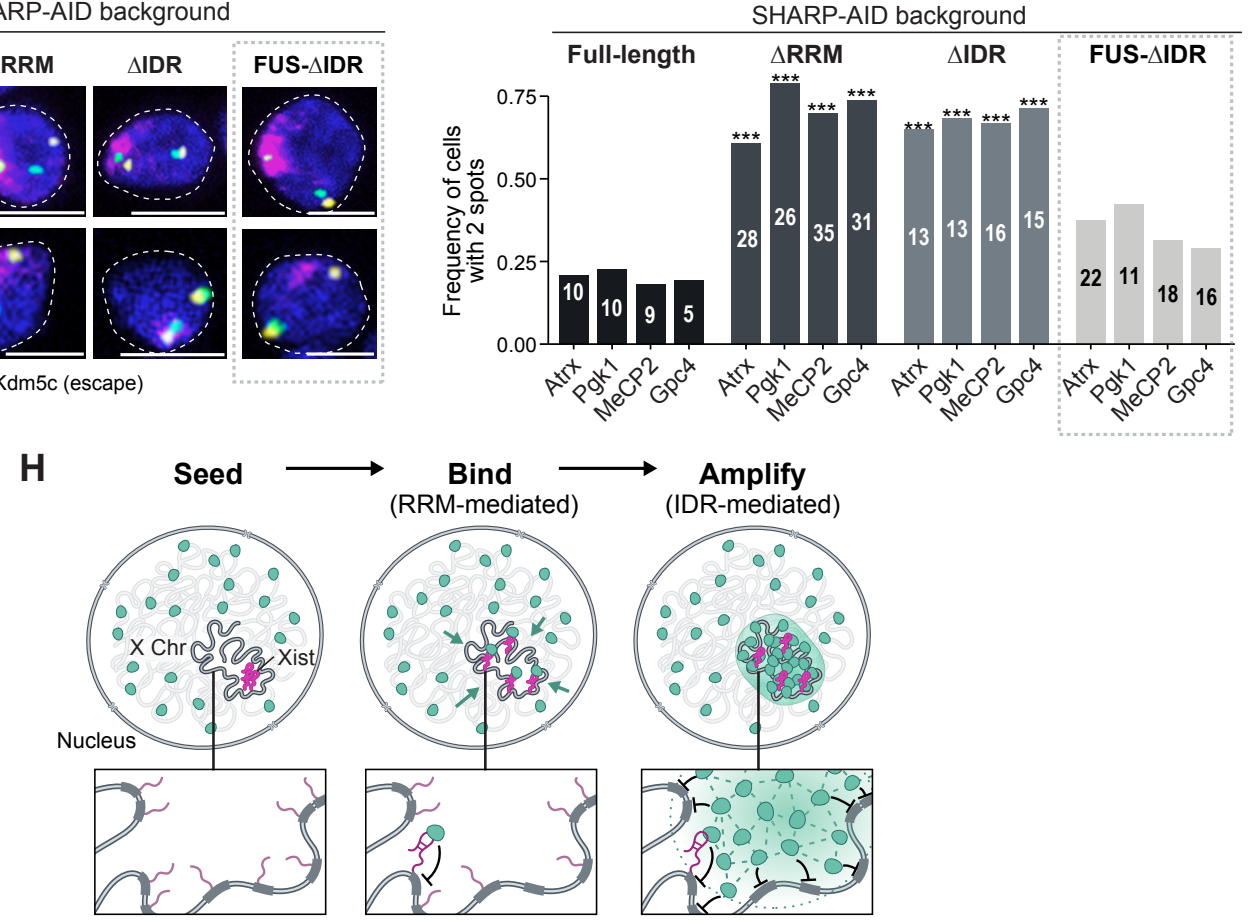

Figure 4:

continued on page 9 
bioRxiv preprint doi: https://doi.org/10.1101/2021.10.27.466149; this version posted October 28, 2021. The copyright holder for this preprint (which was not certified by peer review) is the author/funder, who has granted bioRxiv a license to display the preprint in perpetuity. It is made available under aCC-BY-NC-ND 4.0 International license.

Figure 4: SHARP binding to RNA (via RRM) and formation of assemblies (via IDRs) are both required for chromosome-wide gene silencing

(A) Illustration of our RNA FISH measurements in dox-inducible female mESCs. Green: genes that are silenced upon Xist induction; yellow: genes that escape XCI (remain active after Xist induction), magenta: Xist. (B) RNA FISH images representing (left to right): wildtype (no dox); wildtype (with dox); SHARP-KO (with dox); auxin-treated SHARP-AID (with dox). Cells were stained for DAPI (blue) and probed for Xist (magenta), escape gene Kdm5c (yellow), and silenced genes Atrx or Pgk1 (green). Images shown as max. projections; scale bars show $10 \mu \mathrm{m}$. (C) Quantification of multiple RNA FISH images (Fig. 1B) representing the frequency of cells containing two actively transcribed alleles (left to right): wildtype (no dox); wildtype (with dox); SHARP-KO (with dox); auxin-treated SHARP-AID (with dox).

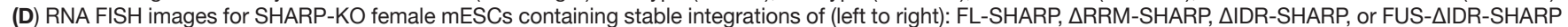
after $>72$ hours of dox induction. Cells were stained for DAPI (blue) and probed for Xist (magenta), escape gene Kdm5c (yellow), and silenced genes Atrx or Pgk1 (green). Images shown as max projections; scale bars show $10 \mu \mathrm{m}$. (E) Quantification of RNA-FISH images representing the frequency of cells containing two actively transcribed alleles for the various SHARP rescue constructs in SHARP-KO female mESCs. (F) RNA FISH images for SHARP-AID female mESCs containing stable integrations of (left to right): FL-SHARP, $\triangle$ RRM-SHARP, $\triangle$ IDR-SHARP, or FUS- $\triangle I D R-S H A R P$ after $>72$ hours of dox induction and auxin treatment. Cells were stained for DAPI (blue) and probed for Xist (magenta), escape gene Kdm5c (yellow), and silenced genes Atrx or Pgk1 (green). Images shown as max projections; scale bars show $10 \mu \mathrm{m}$. (G) Quantification of RNA-FISH images representing the frequency of cells containing two actively transcribed alleles for the various SHARP rescue constructs in SHARP-AID female mESCs. In all panels, only cells containing two escape gene spots (Kdm5c, Kdm6a) and Xist (for dox-induced conditions) were scored for the number of silenced gene spots. Asterisks represent p-values calculated for two proportion Z-test, distributions compared to FL group, ${ }^{*} 0.05$, ${ }^{* *} 0.01,{ }^{* * *} 0.001$. (H) Schematic illustration of the spatial amplification mechanism by which Xist RNA (magenta) can act to amplify SHARP (green) recruitment and gene silencing across the $\mathrm{X}$ chromosome.

population of cells (using RT-qPCR; Fig. S5D). Then, for each RAP sample, we computed the level of Xist RNA enrichment on the $X$ chromosome $(X)$ by quantifying the proportion of sequencing reads that align to the $X$ relative to autosomes (A). We compared this to the expected $X: A$ ratio observed in the unselected genomic DNA sample (input) (see Methods). In all cases we observed clear enrichment of Xist on the $X$ chromosome (Fig. 5D). However, we observed a steady decrease in $\mathrm{X}: \mathrm{A}$ enrichment as Xist concentration increased. For example, in samples treated with $3 x$ dox ( $\sim 5$ fold above endogenous levels) we observed a $>2$-fold reduction in the $\mathrm{X}: \mathrm{A}$ enrichment compared to samples treated with $0.25 \mathrm{x}$ dox (which approximates endogenous Xist levels) (Fig. 5E).

Because Xist spreads via 3D diffusion, we hypothesized that the autosomal regions that become occupied at increasing dox concentrations are those that are closest to the Xist locus in 3D space. To test this, we computed the 3D contact frequency between the Xist genomic locus and all 1 megabase genomic regions across autosomes [56] (Fig. 5F, S5E). Interestingly, we observed a strong correlation between autosomal regions that are closest to the Xist locus and those that display increased Xist RNA occupancy in the $3 \mathrm{x}$ dox condition (Fig. 5G; Fig. S5F). Taken together, these results indicate that sub-stoichiometric expression of Xist (low number of Xist molecules) is a critical mechanism by which cells limit Xist spreading to autosomal regions and ensure its specificity to the $X$ chromosome (Fig. 5H).

Given that low Xist expression levels are critical for ensuring specificity to the $X$ chromosome, we considered possible mechanisms that may act to limit its expression level in vivo. One long puzzling observation is that even though Xist and SHARP accumulate in proximity to the Xist transcriptional locus $[16,17,24]$, the Xist gene remains actively transcribed - an essential requirement for $\mathrm{XCl}$. We hypothesized that Xist-SHARP accumulation at its own locus might act to control the level of Xist expression. To test this, we used the auxin degradable SHARP system (SHARP-AID) and measured Xist expression levels upon dox-induction or RA-differentiation. In both cases, we found that depletion of SHARP leads to an 2-fold average upregulation of Xist expression (Fig. 5I, Fig. S5G). Consistent with the fact that increased Xist expression leads to an increase in Xist spreading within the nucleus, we observed that degradation of SHARP led to a higher percentage of the nucleus being occupied by Xist (Fig. 5J). Because negative feedback loops often act as regulatory mechanisms to restrict production levels within a defined range [57-60], our results suggest that Xist may act to suppress its own production to ensure specificity to the $X$ (Fig. 5K).

\section{DISCUSSION}

Our results demonstrate a critical spatial amplification mechanism by which Xist balances two essential but countervailing regulatory objectives: specificity to the $X$ and chromosome-wide gene silencing (Fig. 6). We showed that low Xist RNA levels are necessary to ensure specificity to its target sites on the X. Yet, it creates another challenge in that the RNA is expressed at sub-stoichiometric levels compared to its regulatory targets and therefore cannot localize at each of them. We showed that Xist overcomes this challenge by driving non-stoichiometric recruitment of SHARP to amplify its abundance across the $\mathrm{X}$ chromosome and enable chromosome-wide gene silencing. Although a stoichiometric model (where Xist recruits SHARP through direct binding and localizes at each of its target genes) would also enable chromosome-wide silencing, it would require Xist to be expressed at dramatically higher levels and therefore reduce Xist specificity to the $X$. While the spatial amplification mechanism can achieve both specificity and robust silencing, balancing these two competing objectives requires precise quantitative control of Xist RNA levels. Our results highlight a negative feedback loop whereby Xist (through SHARP) may act to suppress production of its own RNA in order to restrict its ability to spread beyond the $\mathrm{X}$ (Fig. 6 ). 
bioRxiv preprint doi: https://doi.org/10.1101/2021.10.27.466149; this version posted October 28, 2021. The copyright holder for this preprint (which was not certified by peer review) is the author/funder, who has granted bioRxiv a license to display the preprint in perpetuity. It is made available under aCC-BY-NC-ND 4.0 International license.

A

\section{Dox-inducible Xist expression}

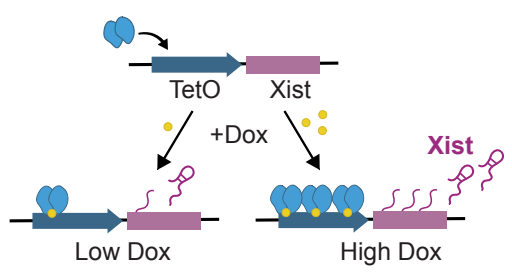

B

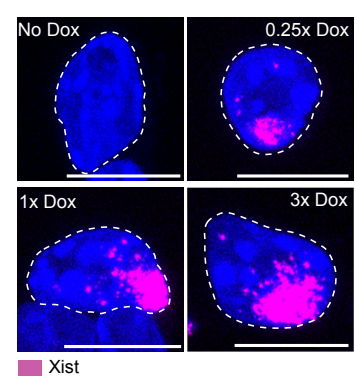

H

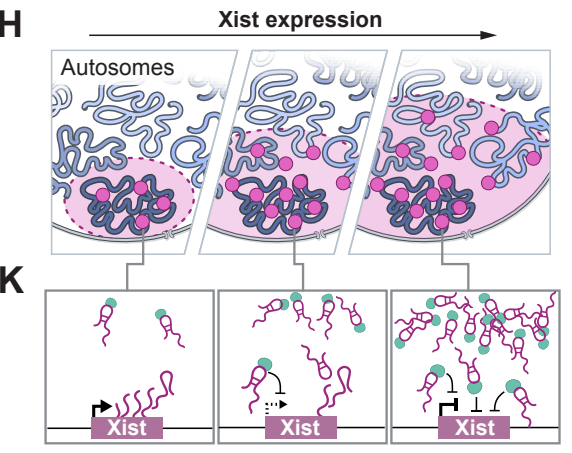

D
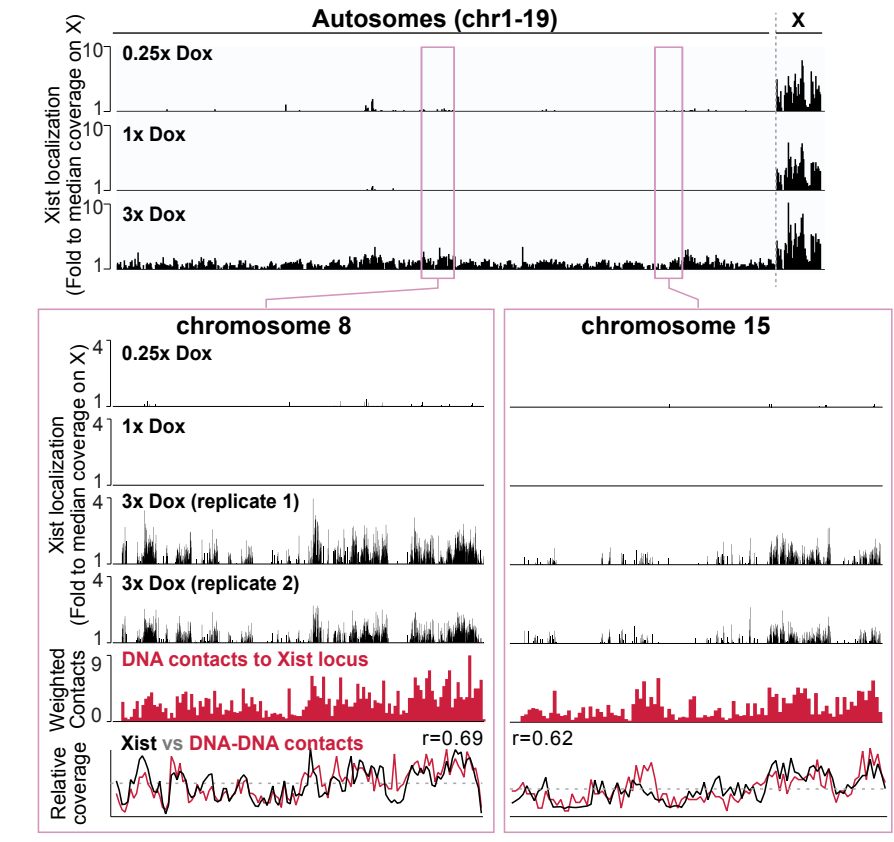
$\mathbf{X}$
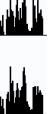

\section{$\mathbf{F}$}

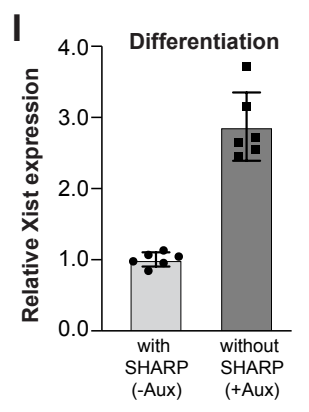

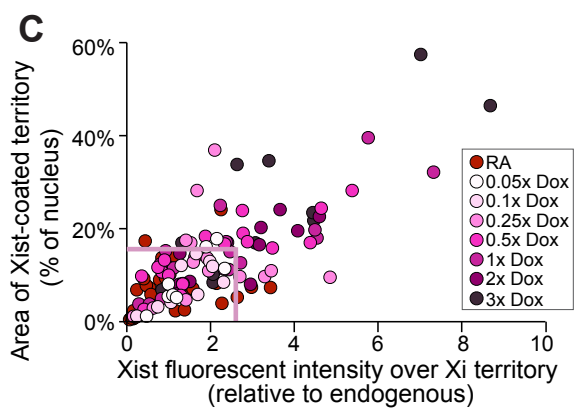

E
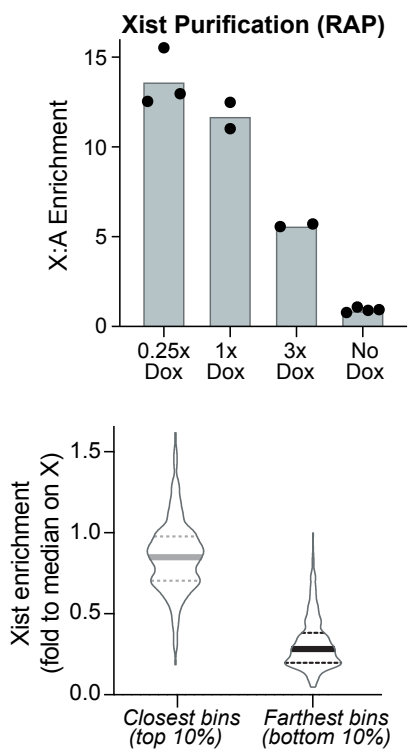

Distance to Xist locus (DNA-DNA contacts)
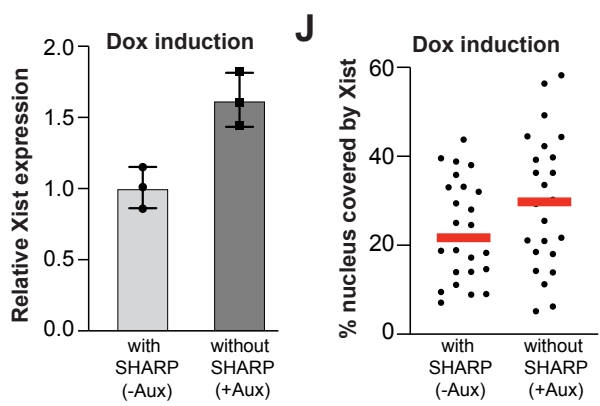

Figure 5: Xist expression levels limit its ability to spread to autosomes

(A) Schematic of dox concentration relative to Xist transcription levels in our inducible system. (B) Representative images of Xist localization (magenta) within the nucleus (DAPI) of female mESCs treated with increasing concentrations of dox (no dox, 0.25x, 1x, 3x dox). (C) Quantification of the area covered by the Xist territory as percent of nucleus (based on RNA FISH and DAPI staining, respectively) relative to Xist expression levels (based on total intensity of Xist per cell) in RA differentiated and dox-induced female mESCs. X-axis: Xist expression levels are normalized to the median expression level of RA differentiated cells; box represents the 95th percentile of Xist expression and area covered in RA differentiated cells. (D) Xist enrichment across the genome measured by RNA Antisense Purification (RAP) of Xist followed by DNA sequencing. Scales represent Xist enrichments relative to total genomic DNA in female mESCs treated with $0.25 \mathrm{x}, 1 \mathrm{x}$ and $3 x$ dox. Xist enrichment across the genome normalized to the median coverage across the $X(50 \%$ of $X$ chromosome bins are 1$)$ (E) Overall Xist enrichment on the $\mathrm{X}$ chromosome relative to autosomes in $0.25 \mathrm{x}, 1 \mathrm{x}, 3 \mathrm{x}$ dox-induced and uninduced female mESCs (no dox) as measured by the proportion of sequencing reads that align to the $X$ relative to autosomes (A) in RAP-DNA samples normalized to the expected $X: A$ ratio observed in the unselected genomic DNA sample (input). Dots represent individual RAP-DNA replicates, bars represent mean value. (F) Xist enrichment over chr8 (right) and chr15 (left) measured by RAP; Xist enrichment relative to the median coverage on the X (black bars), DNA contact frequency [56] of each region relative to the Xist locus (red bars), bottom: overlay between Xist enrichment and 3D contacts with the Xist locus. (G) Levels of Xist enrichment in the 3x dox sample over $1 \mathrm{Mb}$ autosomal regions that are closest to Xist locus (left, top 10\%) or furthest from Xist locus (right, bottom 10\%) based on 3D distance maps calculated from DNA-SPRITE data [56]; Bold lines represent median values, dotted lines represent 25th and 75th percentile. (H) Schematic depicting increased Xist spreading in the nucleus with increasing Xist expression levels. (I) Relative Xist expression in RA differentiated (left) and dox-induced (right) female SHARP-AID mES cells in the absence or presence of auxin as measured by RT-qPCR. Fold change values were calculated by normalizing to the median of RA differentiated or dox-induced cells in the absence of auxin. Individual points show each replicate value. (J) Quantification of percent of nucleus occupied by Xist in dox-induced SHARP-AID cells in the absence or presence of SHARP as measured by RNA FISH (Xist) and DAPI staining (nucleus). (K) Model illustrating how Xist (through SHARP) may suppress production of its own RNA at its gene locus through negative feedback. 


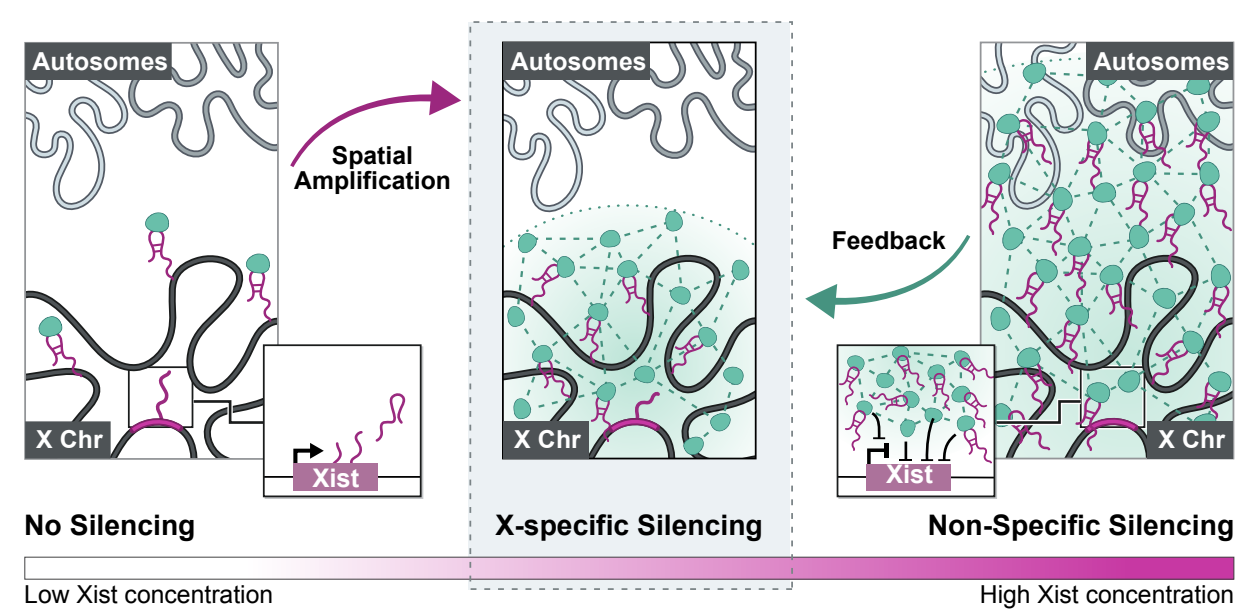

Figure 6: The spatial amplification mechanism balances chromosome-wide silencing and specificity to the $X$ chromosome.

A schematic illustrating components of the spatial amplification mechanism. Left: Xist is expressed, accumulates on the $X$ chromosome through 3D diffusion from its transcription locus, binds directly to SHARP and recruits it to the X chromosome in a stoichiometric manner. Zoom-in: At low overall expression, the Xist gene remains actively transcribed. Middle: Once SHARP molecules achieve sufficiently high spatial concentration over X, they form concentration-dependent assemblies (spatial amplification) that enable non-stoichiometric accumulation of SHARP on the $X$ and chromosome-wide silencing. Right: If $X$ ist expression levels get too high, the RNA would start to spread to autosomal regions. At high concentrations, Xist recruits more SHARP molecules to its own locus which can suppress transcription of its own gene (right zoom-panel). This acts to reduce Xist spreading and restrain Xist-SHARP complex on the X chromosome (feedback).

This spatial amplification mechanism is dependent on the fact that Xist can form a high concentration territory on the $X$ through $3 D$ diffusion from its transcription locus (seed). In this way, Xist binding to SHARP increases its concentration on the $X$ (recruit) and enables formation of concentration-dependent protein assemblies that amplify recruitment of repressive proteins to enable chromosome-wide gene silencing (amplify, Fig. 4H). Furthermore, because Xist spreads to its targets via 3D diffusion from its transcription locus, localization specificity is sensitive to its overall expression levels (restriction, Fig. 5H).

Beyond Xist, this spatial amplification mechanism is likely to represent a more general mechanism by which IncRNAs can balance specificity to, and robust control, of their regulatory targets because many IncRNAs share these same properties. Specifically, many hundreds of IncRNAs have been shown to form highconcentration territories in spatial proximity to their transcription sites (seed) and can directly bind and recruit different regulatory proteins (recruit), including those that contain long IDRs [61] (e.g. HP1 [62,63] and SHARP). In this way, IncRNA-mediated recruitment may enable spatial amplification of regulatory proteins and robust regulation of their more abundant targets (amplification). Because many IncRNAs localize in 3D proximity to their targets, low expression levels may similarly be important for ensuring specificity to their genomic DNA targets (restriction).

In this way, spatial amplification may provide a mechanistic answer to two long-standing questions in the IncRNA-field: (i) why many IncRNAs are expressed at relatively low levels and (ii) how low abundance
IncRNAs can effectively regulate their more abundant targets.

\section{ACKNOWLEDGEMENTS}

We thank Michael Elowitz, Shasha Chong, Isabel Goronzy, and Drew Honson for their critical comments about the manuscript. We would like to thank Amy Pandya-Jones for sharing her experience with SHARP visualization using pre-extraction followed by immunostaining, and Edith Heard's laboratory for sharing their cell lines and cell culture protocols. We would like to thank Amy Chow for helpful comments and support with the cell culture work at Guttman laboratory, Biological Imaging Facility at Caltech for their help with microscopy, and Flow Cytometry Facility at Caltech for their help with cell sort. We also thank Shawna Hiley for contributions to writing and editing this manuscript, Marie Bao for her editorial assistance, and Inna-Marie Strazhnik for illustrations. This work was supported by the NIH 4DN program (U01 DA040612 and U01 HL130007), NIH Directors' Transformative Research Award (R01 DA053178), the New York Stem Cell Foundation, and funds from the California Institute of Technology. M.G. is a NYSCF-Robertson Investigator. J.W.J. was supported by a Caltech BBE post-doctoral fellowship. A.K.B. was funded by NHLBI F30-HL136080 and the USC MD/PhD Program.

\section{AUTHOR NOTE}

While we were working on this manuscript, our long-time collaborators were exploring the localization of various proteins involved in $\mathrm{XCl}$ using super-resolution microcopy. In parallel, they made a similar observation regarding the dynamics of Xist and SHARP localization and recently reported this in Markaki et al [19]. Some of the authors on this manuscript are also authors on that manuscript because we openly shared several reagents used for their study, including the SHARP mutant constructs that we generated for this manuscript.

\section{AUTHOR CONTRIBUTIONS}

J.W.J. conceived of this project with M.G. J.W.J. and M.S. performed experiments, analyzed and interpreted data, generated figures, and 
bioRxiv preprint doi: https://doi.org/10.1101/2021.10.27.466149; this version posted October 28, 2021. The copyright holder for this preprint (which was not certified by peer review) is the author/funder, who has granted bioRxiv a license to display the preprint in perpetuity. It is made available under aCC-BY-NC-ND 4.0 International license.

wrote the paper. A.K.B. performed all CLAP sequencing experiments and provided comments and edits for the manuscript. J.T. created the SHARP rescue constructs with A.K.B and assisted with cell culture. M.R.B worked with A.K.B on CLAP sequencing experiments, worked with J.W.J on RAP sequencing experiments, analyzed sequencing data, and provided comments and edits for the manuscript. M.G. conceived of this project with J.W.J. and oversaw all experiments and analysis, performed analysis and generated figures, and wrote the paper with J.W.J. and M.S.

\section{REFERENCES}

1. Guttman M, Amit I, Garber M, French C, Lin MF, Feldser D, Huarte M, Zuk O, Carey BW, Cassady JP, et al.: Chromatin signature reveals over a thousand highly conserved large non-coding RNAs in mammals. Nature 2009, 458:223-227.

2. Engreitz JM, Haines JE, Perez EM, Munson G, Chen J, Kane M, McDonel PE, Guttman M, Lander ES: Local regulation of gene expression by IncRNA promoters, transcription and splicing. Nature 2016, 539:452-455.

3. Carninci P, Kasukawa T, Katayama S, Gough J, Frith MC, Maeda N, Oyama R, Ravasi T, Lenhard B, Wells C, et al.: The transcriptional landscape of the mammalian genome. Science (80- ) 2005, 309:1559-1563.

4. Lee JT: Lessons from X-chromosome inactivation: long ncRNA as guides and tethers to the epigenome. Genes Dev 2009, 23:1831-1842.

5. Nagano T, Mitchell JA, Sanz LA, Pauler FM, Ferguson-Smith AC, Feil R, Fraser P: The Air Noncoding RNA Epigenetically Silences Transcription by Targeting G9a to Chromatin. Science (80- ) 2008, 322:1717-1720.

6. Dunagin M, Cabili MN, Rinn J, Raj A: Visualization of IncRNA by Single-Molecule Fluorescence In Situ Hybridization. Methods Mol Biol 2015, 1262:3-19.

7. Wang KC, Yang YW, Liu B, Sanyal A, Corces-Zimmerman R, Chen Y, Lajoie BR, Protacio A, Flynn RA, Gupta RA, et al.: A long noncoding RNA maintains active chromatin to coordinate homeotic gene expression. Nature 2011, 472:120-124.

8. Carpenter S, Aiello D, Atianand MK, Ricci EP, Gandhi P, Hall LL, Byron M, Monks B, Henry-Bezy M, Lawrence JB, et al.: A Long Noncoding RNA Mediates Both Activation and Repression of Immune Response Genes. Science (80- ) 2013, 341:789-792.

9. Thomson DW, Dinger ME: Endogenous microRNA sponges: evidence and controversy. Nat Rev Genet 2016, 17:272-283.

10. Kopp F, Mendell JT: Functional classification and experimental dissection of long noncoding RNAs. Cell 2018, 172:393.

11. Penny GD, Kay GF, Sheardown SA, Rastan S, Brockdorff N: Requirement for Xist in $\mathrm{X}$ chromosome inactivation. Nature 1996, 379:131-137.

12. Marahrens $\mathrm{Y}$, Loring $\mathrm{J}$, Jaenisch R: Role of the Xist gene in $\mathrm{X}$ chromosome choosing. Cell 1998, 92:657-64.

13. Dyer KA, Canfield TK, Gartler SM: Molecular cytological differentiation of active from inactive $X$ domains in interphase: implications for $X$ chromosome inactivation. Cytogenet Genome Res 1989, 50:116-120.

14. Chaumeil J, Le Baccon P, Wutz A, Heard E: A novel role for Xist RNA in the formation of a repressive nuclear compartment into which genes are recruited when silenced. Genes Dev 2006, 20:2223-2237.

15. Clemson CM, McNeil JA, Willard HF, Lawrence JB: XIST RNA paints the inactive $X$ chromosome at interphase: evidence for a novel RNA involved in nuclear/chromosome structure. J Cell Biol 1996, 132:259-75.

16. Engreitz JM, Pandya-Jones A, Mcdonel P, Shishkin A, Sirokman K, Surka C, Kadri S, Xing J, Goren A, Lander ES, et al.: The Xist IncRNA Exploits Three-Dimensional Genome Architecture to Spread Across the X Chromosome. Science 2013, 341:1237973.

17. Simon MD, Pinter SF, Fang R, Sarma K, RutenbergSchoenberg M, Bowman SK, Kesner BA, Maier VK, Kingston RE, Lee JT: High-resolution Xist binding maps reveal two-step spreading during X-chromosome inactivation. Nature 2013 , 504:465-469.

18. Sunwoo H, Wu JY, Lee JT: The Xist RNA-PRC2 complex at 20-nm resolution reveals a low Xist stoichiometry and suggests a hit-and-run mechanism in mouse cells. Proc Natl Acad Sci U S A 2015, 112:E4216-E4225.

19. Markaki Y, Gan Chong J, Luong C, Tan SY, Wang Y, Jacobson EC, Maestrini D, Dror I, Mistry BA, Schöneberg J, et al.: Xist-seeded nucleation sites form local concentration gradients of silencing proteins to inactivate the X-chromosome Equal contribution. bioRxiv 2020, doi:10.1101/2020.11.22.393546.

20. Rodermund L, Coker H, Oldenkamp R, Wei G, Bowness J, Rajkumar B, Nesterova T, Susano Pinto DM, Schermelleh L, Brockdorff N: Time-resolved structured illumination microscopy reveals key principles of Xist RNA spreading. Science (80- ) 2021, 372:eabe7500.

21. Marahrens Y, Panning B, Dausman J, Strauss W, Jaenisch R: Xist-deficient mice are defective in dosage compensation but not spermatogenesis. Genes Dev 1997, 11:156-166.

22. McHugh CA, Chen CK, Chow A, Surka CF, Tran C, McDonel P, Pandya-Jones A, Blanco M, Burghard C, Moradian A, et al.: The Xist IncRNA interacts directly with SHARP to silence transcription through HDAC3. Nature 2015, 521:232-236.

23. Wutz A, Rasmussen TP, Jaenisch R: Chromosomal silencing and localization are mediated by different domains of Xist RNA. Nat Genet 2002, 30:167-174.

24. Dossin F, Pinheiro I, Żylicz JJ, Roensch J, Collombet S, Le Saux A, Chelmicki T, Attia M, Kapoor V, Zhan Y, et al.: SPEN integrates transcriptional and epigenetic control of X-inactivation. Nature 2020, 578:455-460.

25. Chu C, Zhang QC, da Rocha ST, Flynn RA, Bharadwaj M, Calabrese JM, Magnuson T, Heard E, Chang HY: Systematic Discovery of Xist RNA Binding Proteins. Cell 2015, 161:404-416.

26. Lu Z, Zhang C, Lee B, Mesirov JP, Cech TR, Correspondence HYC, Zhang QC, Flynn RA, Smith MA, Robinson JT, et al.: RNA Duplex Map in Living Cells Reveals Higher-Order Transcriptome Structure. Cell 2016, 165:1267-1279.

27. Minajigi A, Froberg JE, Wei C, Sunwoo H, Kesner B, Colognori D, Lessing D, Payer B, Boukhali M, Haas W, et al.: A comprehensive Xist interactome reveals cohesin repulsion and an RNA-directed chromosome conformation. Science 2015, 349:aab2276-aab2276.

28. Cirillo D, Blanco M, Armaos A, Buness A, Avner P, Guttman M, Cerase A, Tartaglia GG: Quantitative predictions of protein interactions with long noncoding RNAs. Nat Methods 2016, 14:5-6.

29. Żylicz JJ, Bousard A, Žumer K, Dossin F, Mohammad E, da Rocha ST, Schwalb B, Syx L, Dingli F, Loew D, et al.: The 
bioRxiv preprint doi: https://doi.org/10.1101/2021.10.27.466149; this version posted October 28, 2021. The copyright holder for this preprint (which was not certified by peer review) is the author/funder, who has granted bioRxiv a license to display the preprint in perpetuity. It is made available under aCC-BY-NC-ND 4.0 International license.

Implication of Early Chromatin Changes in X Chromosome Inactivation. Cell 2019, 176:182-197.

30. You SH, Lim HW, Sun Z, Broache M, Won KJ, Lazar MA: Nuclear receptor co-repressors are required for the histonedeacetylase activity of HDAC3 in vivo. Nat Struct Mol Biol 2013, 20:182-187.

31. Shi Y, Downes M, Xie W, Kao HY, Ordentlich P, Tsai CC, Hon M, Evans RM: Sharp, an inducible cofactor that integrates nuclear receptor repression and activation. Genes Dev 2001, 15:1140-1151.

32. Monfort A, Wutz A: Identification of Spen as a Crucial Factor for Xist Function through Forward Genetic Screening in Haploid Embryonic Stem Cells. Cell Rep 2015, 12:554-561.

33. Moindrot B, Cerase A, Coker H, Masui O, Grijzenhout A, Pintacuda G, Schermelleh L, Nesterova TB, Brockdorff N: A Pooled shRNA Screen Identifies Rbm15, Spen, and Wtap as Factors Required for Xist RNA-Mediated Silencing. Cell Rep 2015, 12:562-572.

34. Nesterova TB, Wei G, Coker H, Pintacuda G, Bowness JS, Zhang T, Almeida M, Bloechl B, Moindrot B, Carter EJ, et al.: Systematic allelic analysis defines the interplay of key pathways in X chromosome inactivation. Nat Commun 2019, 10:3129.

35. Wutz A, Jaenisch R: A shift from reversible to irreversible $X$ inactivation is triggered during ES cell differentiation. Mol Cell 2000, 5:695-705.

36. Lee JT, Strauss WM, Dausman JA, Jaenisch R: A 450 kb Transgene Displays Properties of the Mammalian X-Inactivation Center. Cell 1996, 86:83-94.

37. Hall LL, Byron M, Sakai K, Carrel L, Willard HF, Lawrence JB: An ectopic human XIST gene can induce chromosome inactivation in postdifferentiation human HT-1080 cells. Proc Natl Acad Sci 2002, 99:8677-8682.

38. Pacini G, Dunkel I, Mages N, Mutzel V, Timmermann B, Marsico A, Schulz EG: Integrated analysis of Xist upregulation and $\mathrm{X}$-chromosome inactivation with single-cell and singleallele resolution. Nat Commun 2021, 12:1-17.

39. Schulz EG, Meisig J, Nakamura T, Okamoto I, Sieber A, Picard C, Borensztein M, Saitou M, Blüthgen N, Heard E: The two active $\mathrm{X}$ chromosomes in female ESCs block exit from the pluripotent state by modulating the ESC signaling network. Cell Stem Cell 2014, 14:203-216.

40. De Andrade E Sousa LB, Jonkers I, Syx L, Dunkel I, Chaumeil J, Picard C, Foret B, Chen CJ, Lis JT, Heard E, et al.: Kinetics of Xist-induced gene silencing can be predicted from combinations of epigenetic and genomic features. Genome Res 2019, 29:1087-1099.

41. Arieti F, Gabus C, Tambalo M, Huet T, Round A, Thore S: The crystal structure of the Split End protein SHARP adds a new layer of complexity to proteins containing RNA recognition motifs. Nucleic Acids Res 2014, 42:6742-6752.

42. Newberry EP, Latifi T, Towler DA: The RRM domain of MINT, a novel Msx2 binding protein, recognizes and regulates the rat osteocalcin promoter. Biochemistry 1999, 38:10678-10690.

43. Hyman AA, Weber CA, Jülicher F: Liquid-Liquid Phase Separation in Biology. Annu Rev Cell Dev Biol 2014, 30:39-58.

44. Lin Y, Currie SL, Rosen MK: Intrinsically disordered sequences enable modulation of protein phase separation through distributed tyrosine motifs. J Biol Chem 2017, 292:19110-19120.

45. Shin Y, Brangwynne CP: Liquid phase condensation in cell physiology and disease. Science (80- ) 2017, 357:eaaf4382.

46. Boija A, Klein IA, Sabari BR, Ihn Lee T, Taatjes DJ, Young
Correspondence RA: Transcription Factors Activate Genes through the Phase-Separation Capacity of Their Activation Domains In Brief Activation domains from a diverse array of mammalian and yeast transcription factors form phaseseparated condensates with Mediator to activate. Cell 2018, 175.

47. Bhat P, Honson D, Guttman M: Nuclear compartmentalization as a mechanism of quantitative control of gene expression. Nat Rev Mol Cell Biol 20212210 2021, 22:653-670.

48. McSwiggen DT, Mir M, Darzacq X, Tjian R: Evaluating phase separation in live cells: diagnosis, caveats, and functional consequences. Genes Dev 2019, 33:1619-1634.

49. Banani SF, Rice AM, Peeples WB, Lin Y, Jain S, Parker R, Rosen MK: Compositional Control of Phase-Separated Cellular Bodies. Cell 2016, 166:651-663.

50. Hnisz D, Shrinivas K, Young RA, Chakraborty AK, Sharp PA: A Phase Separation Model for Transcriptional Control. Cell 2017, 169:13-23.

51. Kato M, Han TW, Xie S, Shi K, Du X, Wu LC, Mirzaei H, Goldsmith EJ, Longgood J, Pei J, et al.: Cell-free formation of RNA granules: Low complexity sequence domains form dynamic fibers within hydrogels. Cell 2012, 149:753-767.

52. Bracha D, Walls MT, Wei MT, Zhu L, Kurian M, Avalos JL, Toettcher JE, Brangwynne CP: Mapping Local and Global Liquid Phase Behavior in Living Cells Using PhotoOligomerizable Seeds. Cell 2018, 175:1467-1480.e13.

53. Lin Y, Protter DSW, Rosen MK, Parker R: Formation and Maturation of Phase-Separated Liquid Droplets by RNA-Binding Proteins. Mol Cell 2015, 60:208-219.

54. Choi J, Huebner AJ, Clement K, Walsh RM, Savol A, Lin K, Gu H, Di Stefano B, Brumbaugh J, Kim SY, et al.: Prolonged Mek1/2 suppression impairs the developmental potential of embryonic stem cells. Nature 2017, 548:219-223.

55. Yagi M, Kishigami S, Tanaka A, Semi K, Mizutani E, Wakayama S, Wakayama T, Yamamoto T, Yamada Y: Derivation of ground-state female ES cells maintaining gamete-derived DNA methylation. Nature 2017, 548:224-227.

56. Quinodoz SA, Ollikainen N, Tabak B, Palla A, Schmidt JM, Detmar E, Lai MM, Shishkin AA, Bhat P, Takei Y, et al.: Higher-Order Inter-chromosomal Hubs Shape 3D Genome Organization in the Nucleus. Cell 2018, 174:744-757.e24.

57. Wollerton MC, Gooding C, Wagner EJ, Garcia-Blanco MA, Smith CWJ: Autoregulation of Polypyrimidine Tract Binding Protein by Alternative Splicing Leading to Nonsense-Mediated Decay. Mol Cell 2004, 13:91-100.

58. Ottens F, Gehring NH: Physiological and pathophysiological role of nonsense-mediated mRNA decay. Eur J Physiol 2016, 468:1013-1028.

59. Müller-McNicoll M, Rossbach O, Hui J, Medenbach J: Autoregulatory feedback by RNA-binding proteins. J Mol Cell Biol 2019, 11:930-939.

60. Rossbach O, Hung L-H, Schreiner S, Grishina I, Heiner $\mathrm{M}$, Hui J, Bindereif A: Auto- and Cross-Regulation of the hnRNP L Proteins by Alternative Splicing. Mol Cell Biol 2009 29:1442-1451.

61. Quinodoz SA, Bhat P, Ollikainen N, Jachowicz JW, Banerjee AK, Chovanec P, Blanco MR, Chow A, Markaki Y, Plath K, et al.: RNA promotes the formation of spatial compartments in the nucleus. Cell 2021, In press.

62. Larson AG, Elnatan D, Keenen MM, Trnka MJ, Johnston JB, Burlingame AL, Agard DA, Redding S, Narlikar GJ: Liquid droplet formation by HP1a suggests a role for phase separation in heterochromatin. Nature 2017, 547:236-240. 
bioRxiv preprint doi: https://doi.org/10.1101/2021.10.27.466149; this version posted October 28, 2021. The copyright holder for this preprint

(which was not certified by peer review) is the author/funder, who has granted bioRxiv a license to display the preprint in perpetuity. It is made available under aCC-BY-NC-ND 4.0 International license.

63. Strom AR, Emelyanov A V., Mir M, Fyodorov D V., Darzacq X, Karpen GH: Phase separation drives heterochromatin domain formation. Nature 2017, 547:241-245.

64. Ran FA, Hsu PD, Wright J, Agarwala V, Scott DA, Zhang F: Genome engineering using the CRISPR-Cas9 system. Nat Protoc 2013, 8:2281-2308.

65. Klock HE, Koesema EJ, Knuth MW, Lesley SA: Combining the polymerase incomplete primer extension method for cloning and mutagenesis with microscreening to accelerate structural genomics efforts. Proteins Struct Funct Genet 2008, 71:982-994.

66. Wu SCY, Meir YJJ, Coates CJ, Handler AM, Pelczar P, Moisyadi S, Kaminski JM: piggyBac is a flexible and highly active transposon as compared to Sleeping Beauty, Tol2, and Mos1 in mammalian cells. Proc Natl Acad Sci 2006, 103:15008-15013.

67. Alberti S, Saha S, Woodruff JB, Franzmann TM, Wang J, Hyman AA: A User's Guide for Phase Separation Assays with Purified Proteins. J Mol Biol 2018, 430:4806-4820.

68. Wachsmuth M: Molecular diffusion and binding analyzed with FRAP. Protoplasma 2014, 251:373-382.

69. Koulouras G, Panagopoulos A, Rapsomaniki MA, Giakoumakis NN, Taraviras S, Lygerou Z: EasyFRAP-web: A web-based tool for the analysis of fluorescence recovery after photobleaching data. Nucleic Acids Res 2018, 46:W467-W472.

70. Banerjee AK, Blanco MR, Bruce EA, Honson DD, Chen LM, Chow A, Bhat P, Ollikainen N, Quinodoz SA, Loney C, et al.: SARS-CoV-2 Disrupts Splicing, Translation, and Protein Trafficking to Suppress Host Defenses. Cell 2020, doi:10.1016/j.cell.2020.10.004.

71. Van Nostrand EL, Pratt GA, Shishkin AA, Gelboin-Burkhart C, Fang MY, Sundararaman B, Blue SM, Nguyen TB, Surka $\mathrm{C}$, Elkins $\mathrm{K}$, et al.: Robust transcriptome-wide discovery of RNA-binding protein binding sites with enhanced CLIP (eCLIP). Nat Methods 2016, 13:508-514.

72. Robinson JT, Thorvaldsdóttir H, Winckler W, Guttman M, Lander ES, Getz G, Mesirov JP: Integrative genomics viewer. Nat Biotechnol 2011, 29:24-26. 


\section{SUPPLEMENTAL NOTE}

\section{Xist localization across the $X$ and chromosome-wide silencing}

Previous studies have shown that there are between 60-200 copies of Xist within each nucleus [18,19]. This level of expression is sufficient to drive chromosome-wide silencing across the $>1500$ genes encoded on the $X$. Based on these numbers, Xist cannot simultaneously localize to each gene within each cell because there are not enough Xist molecules present; it must instead mediate silencing over several genes at once (Fig. S5A). As such, Xist localization within individual cells must be heterogenous such that in one cell it localizes at a subset of genes but in another cell it localizes at a different subset of genes.

Based on ensemble measurements, we know that Xist does not preferentially accumulate at specific sequences (e.g., promoters) but instead localizes broadly across the chromosome (Fig. S5B). This means that the Xist RNA molecules within each cell must localize randomly at distinct positions spread across the $>167$ megabases of the chromosome.

Using this information, we can simulate the expected occupancy of Xist across the $X$ within single cells in a manner that would explain the ensemble pattern (Fig. S5B). We find that the likelihood that Xist is present over any given gene within an individual cell is extremely low (on average $<5 \%$ of genes per cell would be covered by Xist) (Fig. S5C). For example, Xist would be expected to localize over any region of Pgk1 in only 7\% of cells (Fig. S5C). As such, if Xist-mediated silencing was solely dependent on such localization, we would expect that this gene would remain active in $>90 \%$ of individual cells. However, using our single cell measurements we observe that this gene is silenced in $>87 \%$ of single cells (Fig. S4C). Therefore, these single cell measurements allow us to measure chromosome-wide silencing when focusing on a subset of $\mathrm{X}$ chromosome genes. 
bioRxiv preprint doi: https://doi.org/10.1101/2021.10.27.466149; this version posted October 28, 2021. The copyright holder for this preprint (which was not certified by peer review) is the author/funder, who has granted bioRxiv a license to display the preprint in perpetuity. It is made available under aCC-BY-NC-ND 4.0 International license.

A Dox-inducible Xist expression

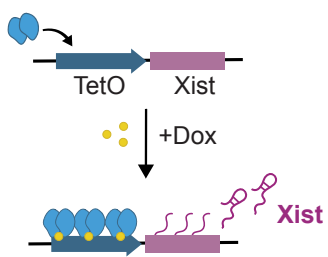

High Dox
D

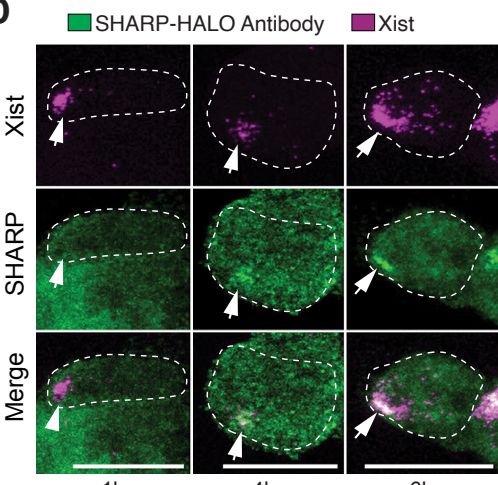

$1 \mathrm{~h}$ Time post Xist induction

F
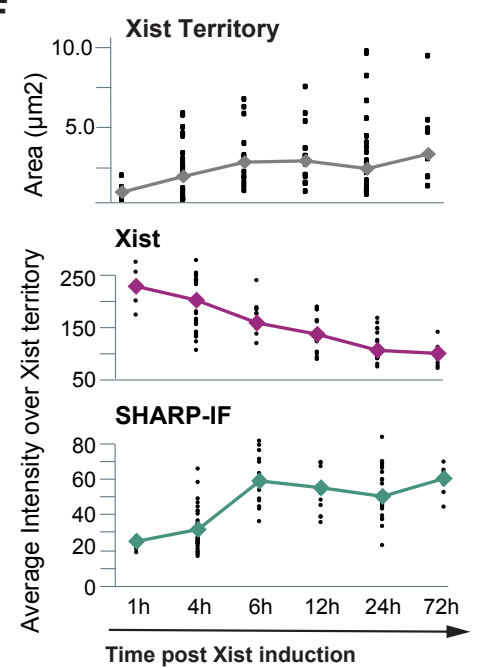

B

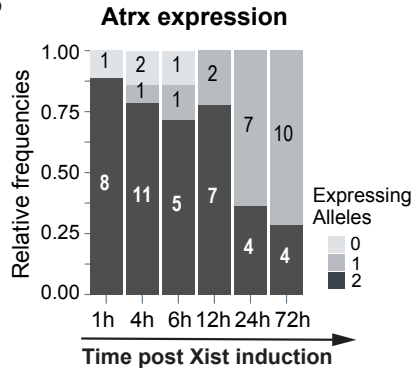

C

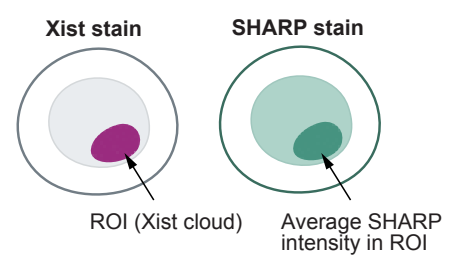

E

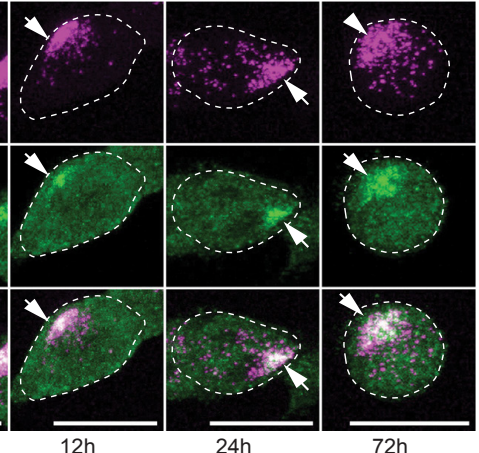

G

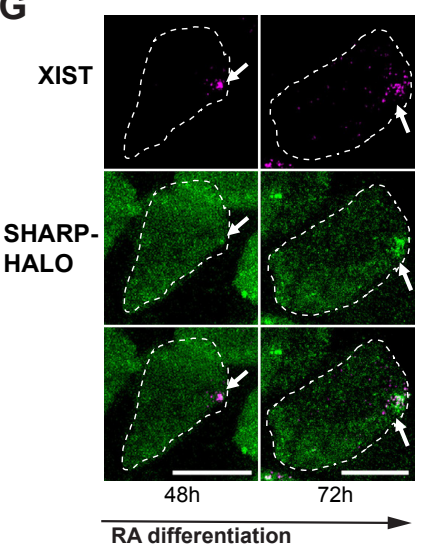

H

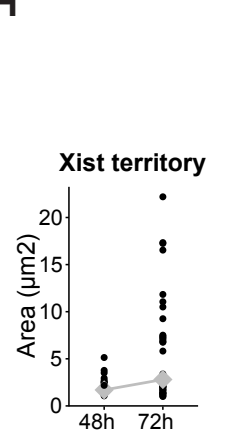

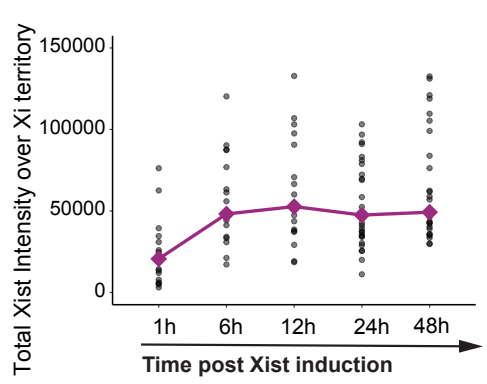

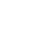


bioRxiv preprint doi: https://doi.org/10.1101/2021.10.27.466149; this version posted October 28, 2021. The copyright holder for this preprint (which was not certified by peer review) is the author/funder, who has granted bioRxiv a license to display the preprint in perpetuity. It is made available under aCC-BY-NC-ND 4.0 International license.

A

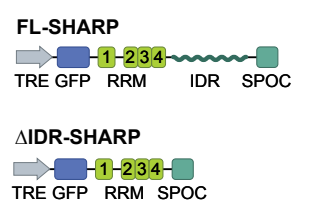

FUS- $\triangle$ IDR-SHARP

TRE FUS MCh RRM SPOC
B

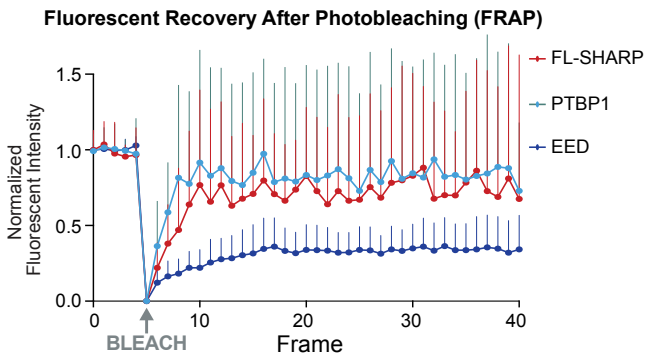

C

D
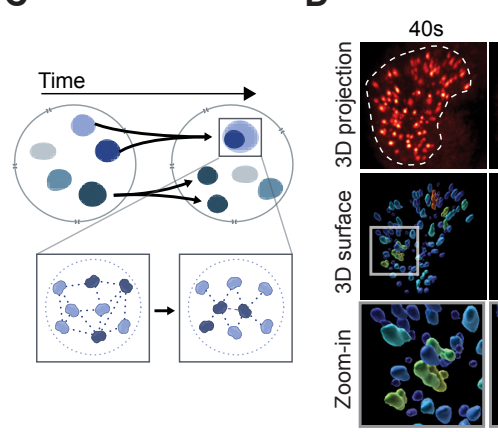

$50 \mathrm{~s}$

$60 \mathrm{~s}$

EGFP-FL-SHARP

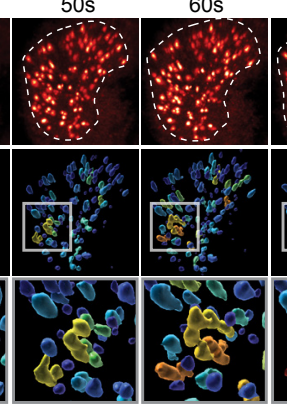

$70 \mathrm{~s}$

$80 \mathrm{~s} \quad 90 \mathrm{~s}$

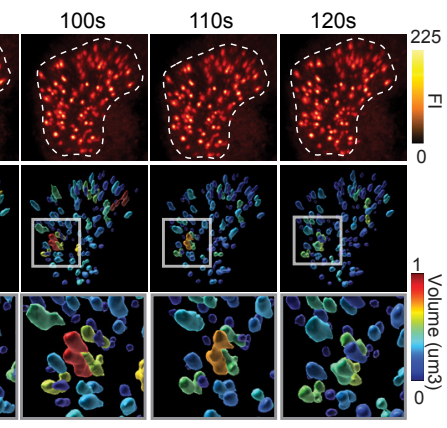

E

$\mathbf{F}$
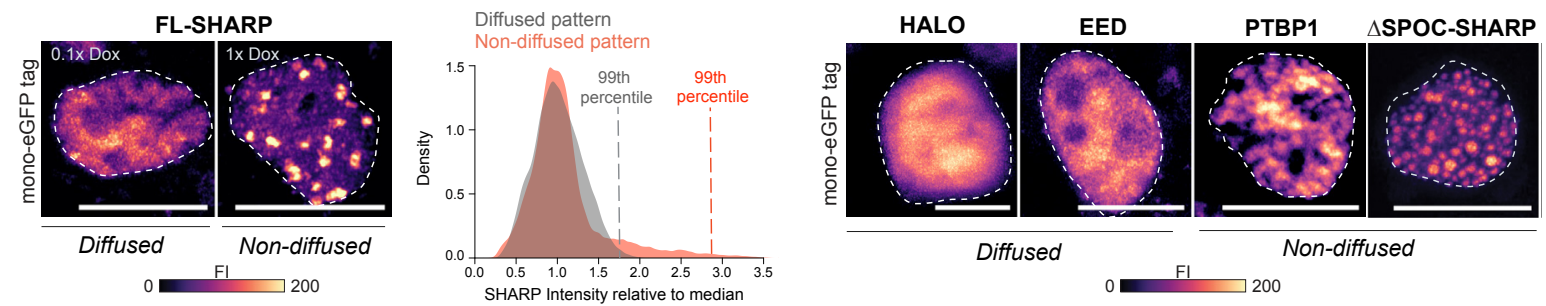

Figure S2: SHARP forms multivalent concentration-dependent assemblies in the nucleus

(A) Schematic of the domains included in the eGFP-tagged FL-SHARP and $\triangle I D R$-SHARP, and the mCherry-tagged FUS- $I$ IDR-SHARP rescue construct used in Fig. 2 and Fig. S2. (B) FRAP recovery curve of eGFP-tagged FL-SHARP (red), positive control PTBP1 (forms assemblies; light blue), and negative control EED (does not form assemblies; dark blue). Error bars represent standard deviation of at least five replicates. (C) Schematic depicting physical characteristics of concentrationdependent assemblies, including foci formation, fission and fusion, and rapid diffusion of proteins within an assembly (inset). (D) Images across nine time-points from a live-cell movie of eGFP-tagged FL-SHARP in transiently transfected HEK293T cells (Movie 1, Movie 2) showing non-diffused, focal organization of SHARP molecules. Top panel: 3D reconstructions of the fluorescent intensity signal; middle panel: 3D volume reconstructions color-coded based on the volume of the focus; bottom panel: zoom-in representing one region of the nucleus that changes volume; Fluorescent Intensity (FI). (E) Comparison of diffused or non-diffused localization patterns of FL-SHARP at different dox concentrations. Left: images representing FL-SHARP expressed with either $0.1 \mathrm{x}$ dox (diffused) or $1 \mathrm{x}$ dox (non-diffused) in transiently transfected HEK293T cells; images shown as max projections; scale bars show $10 \mu m$.; Right: Histograms representing fluorescent intensities for two cells showing diffused and non-diffused localization patterns. The intensity at the 99th percentile of each distribution is shown with the dashed lines. (F) Images representing nuclear localization pattern of eGFP-tagged proteins in transiently transfected HEK293T cells. On the left: proteins that have not been reported to form assemblies (HALO and EED), on the right: an eGFP tagged protein that has been reported to form assemblies (Ptbp1) and $\triangle$ SPOC-SHARP that also forms assemblies. Images shown as max projections; scale bars show $10 \mu \mathrm{m}$. 
bioRxiv preprint doi: https://doi.org/10.1101/2021.10.27.466149; this version posted October 28, 2021. The copyright holder for this preprint (which was not certified by peer review) is the author/funder, who has granted bioRxiv a license to display the preprint in perpetuity. It is made available under aCC-BY-NC-ND 4.0 International license.

A
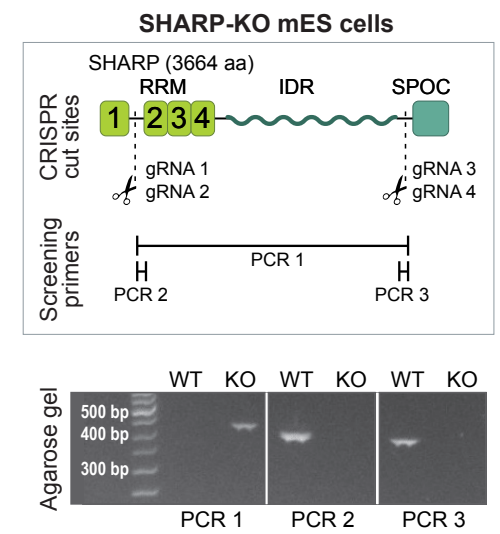

D

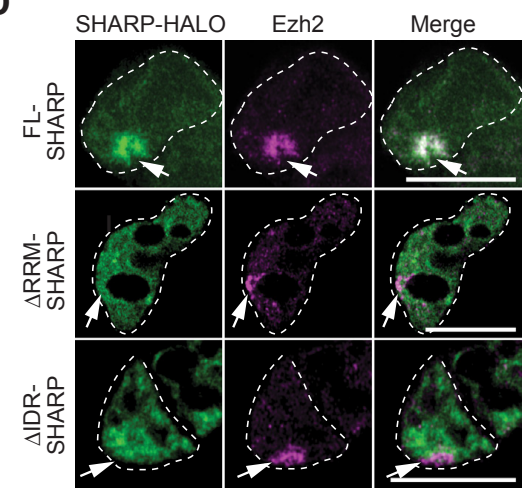

B

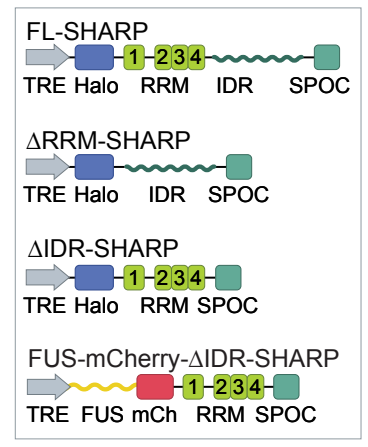

C Generation of stable mES cell lines expressing SHARP constructs

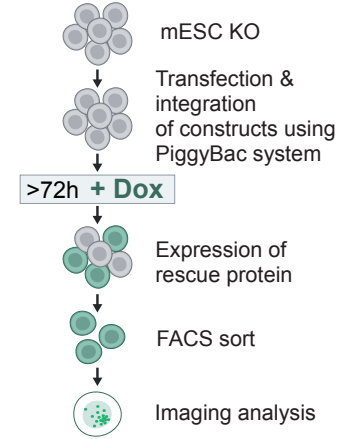

E

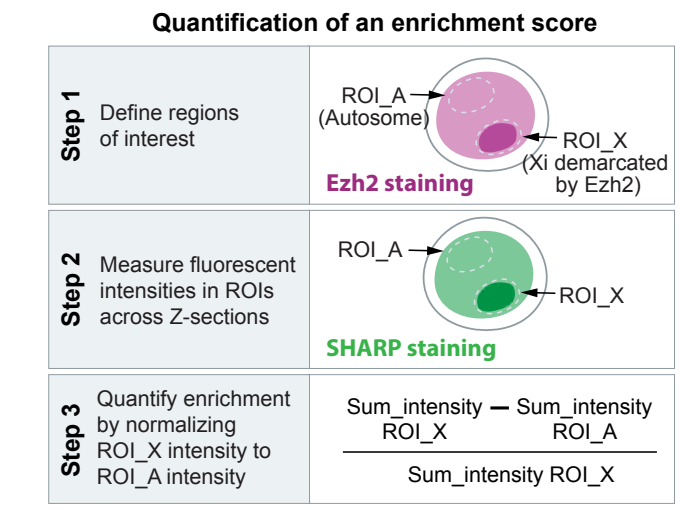

Figure S3: Formation of SHARP assemblies is required for SHARP enrichment on the Xi and is dispensable for Xist binding

(A) Generation of SHARP-KO cell line in TX mESCs. Top: schematic of CRISPR cut sites used to generate SHARP-KO mESCs and PCR primers used to screen for KO clones; bottom: agarose gel confirming homozygous deletion of SHARP in SHARP-KO clone H8 mESCs. (B) Schematics of constructs used to generate rescue cell lines in TX SHARP-KO or TX SHARP-HALO-AID backgrounds. Grey arrow represents dox-inducible promoter; blue box represents HALO (or eGFP) tags used; light green boxes represent RNA Recognition Motifs (RRM); wavy green line represents the Intrinsically Disordered Regions (IDRs); dark green box represents the Spen Paralog and Ortholog C-terminal (SPOC) domain. Full-length SHARP (FL-SHARP), deletion of RRM domain ( $\triangle R R M-S H A R P)$, deletion of IDR domain ( $\triangle I D R-$ SHARP), deletion of IDR domain and insertion of alternative IDR domain from FUS protein (FUS- $\triangle$ IDR-SHARP). (C) Schematic showing experimental workflow for generating and enriching stable SHARP rescue mESCs (FL-SHARP, $\triangle R R M-S H A R P, \triangle I D R-S H A R P$, FUS- $\triangle I D R-S H A R P)$ using constructs from Fig. S3B.

(D) Representative images of SHARP enrichment (HALO, green) over the Xi (anti-Ezh2 immunofluorescence, magenta) in female mESCs containing dox-inducible Xist, genetic deletion of SHARP, and stable integrations of HALO-tagged FL-SHARP, $\triangle$ RRM-SHARP, or $\triangle$ IDR-SHARP. Xist and SHARP rescue constructs induced with doxycycline for 72 hours; images shown as Z-sections; scale bars show $10 \mu \mathrm{m}$. (E) Diagram of image analysis workflow for quantifying SHARP enrichment over the Xi (Fig. 2B). 
bioRxiv preprint doi: https://doi.org/10.1101/2021.10.27.466149; this version posted October 28, 2021. The copyright holder for this preprint (which was not certified by peer review) is the author/funder, who has granted bioRxiv a license to display the preprint in perpetuity. It is made available under aCC-BY-NC-ND 4.0 International license.

A

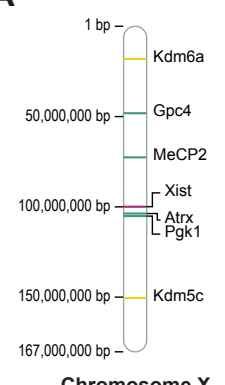

B

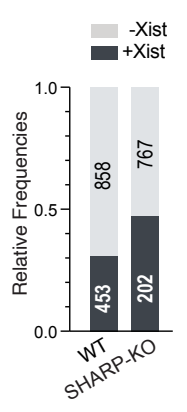

C

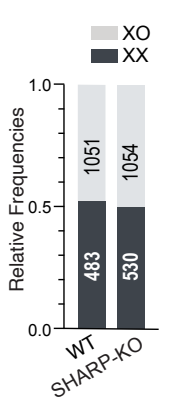

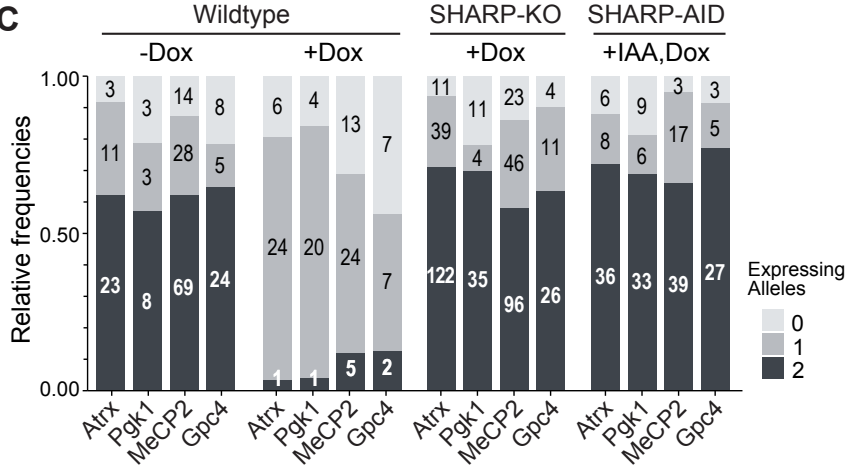

E

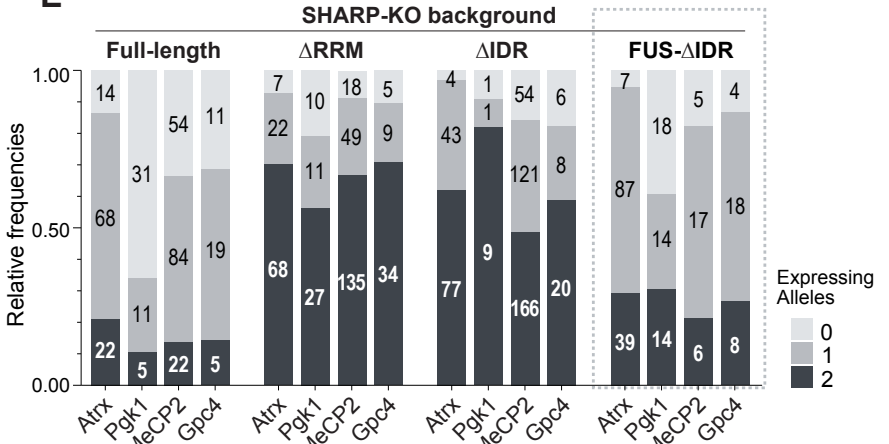

$\mathbf{F}$
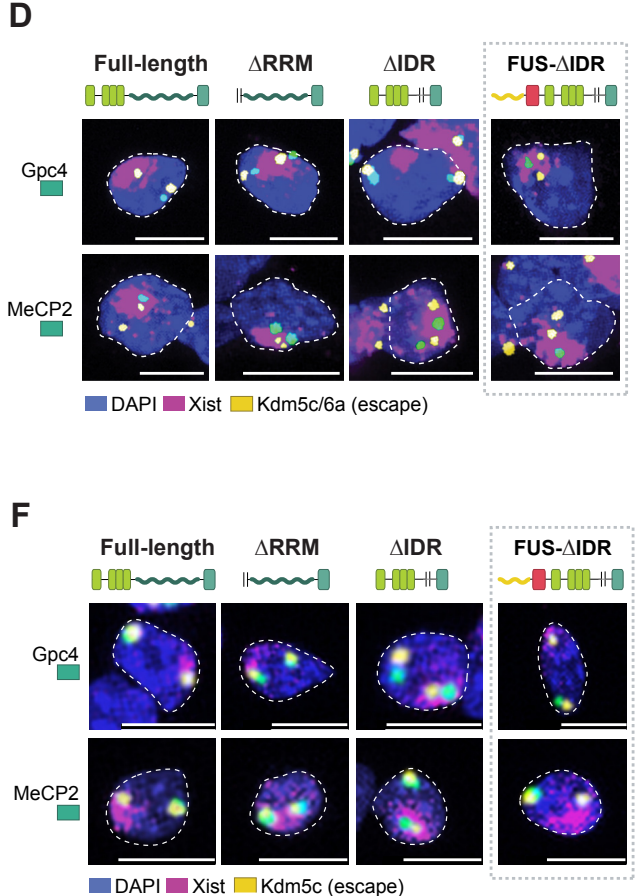

$\mathbf{G}$

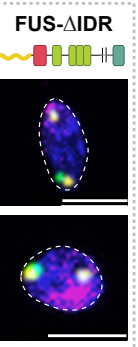

SHARP-AID background

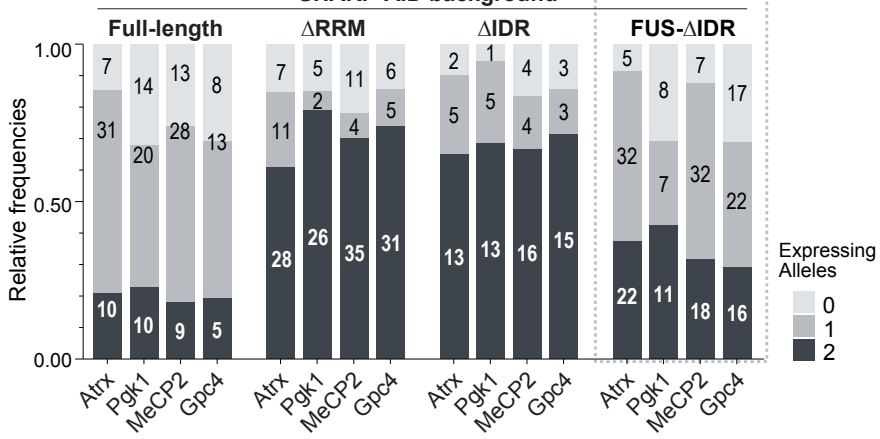

Figure S4: SHARP binding to RNA (via RRM) and formation of assemblies (via IDRs) are both required for chromosomewide gene silencing

(A) Schematic of mouse X chromosome showing the locations of the various genes probed in RNA-FISH experiments. (B) Frequency of Xist induction (left) and X chromosome ploidy (right) in wildtype and SHARP-KO mESCs based on quantification of RNA-FISH images. (C) Quantification of RNA-FISH images (Fig. 4B) representing the frequency of cells containing two, one, or zero actively transcribed alleles. Left to right: wildtype (-dox); wildtype (+dox); dox-induced SHARP-KO; dox-induced, auxin-treated SHARP-AID female mESCs. Only cells containing two escape gene spots (Kdm5c, Kdm6a) and Xist (for dox-induced conditions) were scored for the number of silenced gene spots. (D) RNA-FISH images from SHARP-KO female mESCs containing stable integrations of (left to right): FL-SHARP, $\triangle$ RRM-SHARP, $\triangle I D R-S H A R P$, or FUS- $\triangle$ IDR-SHARP after $>72$ hours of dox induction. Cells were stained for DAPI (blue) and probed for Xist (magenta), escape gene Kdm5c (yellow), and silenced genes Gpc4 or MeCP2 (green). Images shown as max projections; scale bars show $10 \mu \mathrm{m}$. (E) Quantification of RNA-FISH images representing the frequency of cells containing two, one, or zero actively transcribed alleles for the various SHARP rescue constructs in SHARP-KO female mESCs. Only cells containing two escape gene spots (Kdm5c, Kdm6a) and Xist (for dox-induced conditions) were scored for the number of silenced gene spots (Fig. S4D). (F) RNA-FISH images from SHARP-AID female mESCs containing stable integrations of (left to right): FL-SHARP, $\triangle R R M-S H A R P, \triangle I D R-S H A R P$, or FUS- $\triangle$ IDRSHARP after $>72$ hours of dox induction. Cells were stained for DAPI (blue) and probed for Xist (magenta), escape gene Kdm5c (yellow), and silenced genes Gpc4 or MeCP2 (green). Images shown as max projections; scale bars show $10 \mu \mathrm{m}$. (G) Quantification of RNA-FISH images representing the frequency of cells containing two, one, or zero actively transcribed alleles for the various SHARP rescue constructs in SHARP-KO female mESCs. Only cells containing two escape gene spots (Kdm5c, Kdm6a) and Xist (for dox-induced conditions) were scored for the number of silenced gene spots (Fig. S4F). 
bioRxiv preprint doi: https://doi.org/10.1101/2021.10.27.466149; this version posted October 28, 2021. The copyright holder for this preprint (which was not certified by peer review) is the author/funder, who has granted bioRxiv a license to display the preprint in perpetuity. It is made available under aCC-BY-NC-ND 4.0 International license.

A

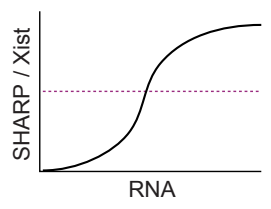

Non-stoichiometric

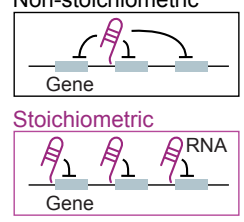

B

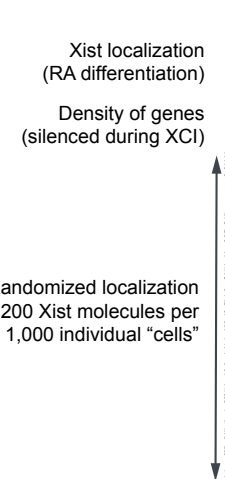

Randomized Xist localization in single cells (permutations)
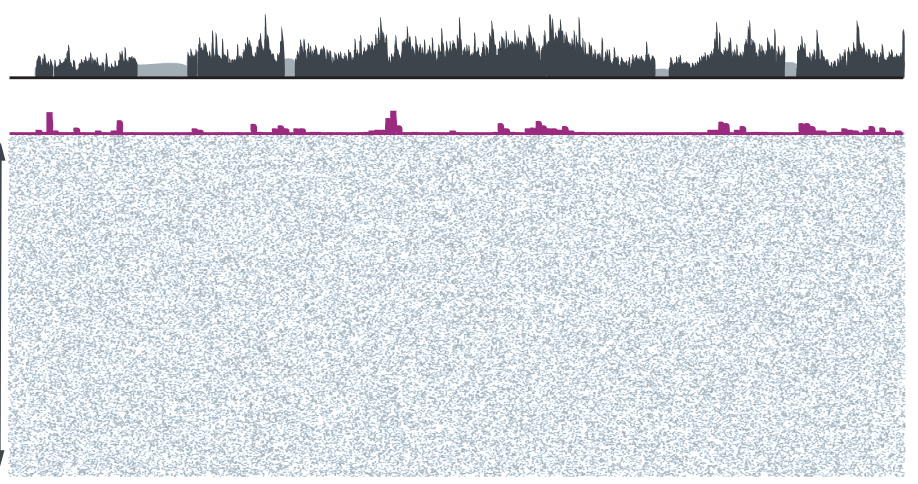

C

Randomized Xist localization in single cells per specific chX genes
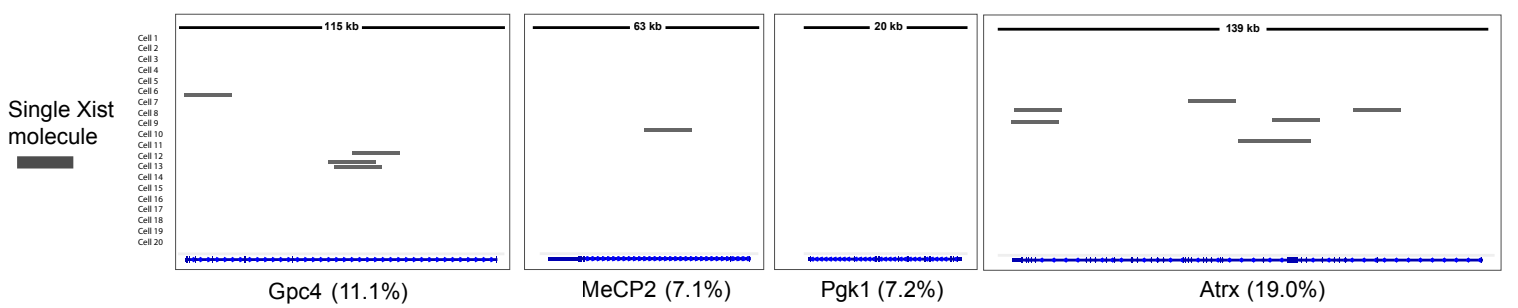

D

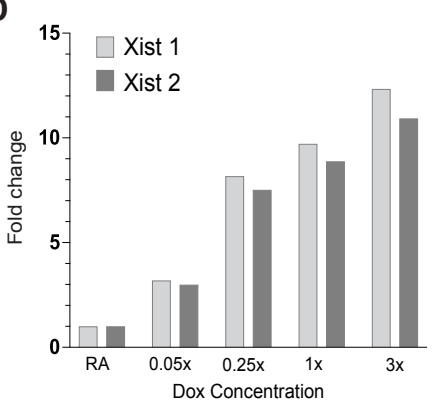

$\mathbf{G}$

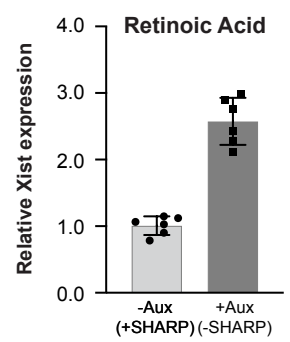

E

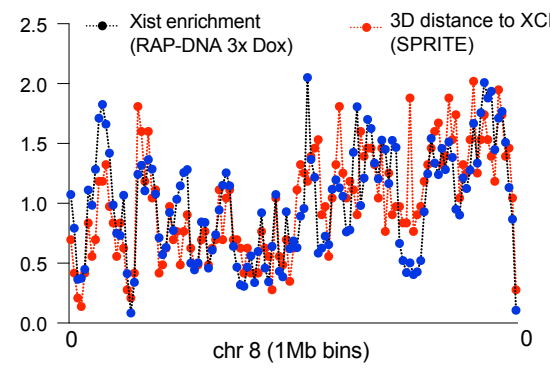

F

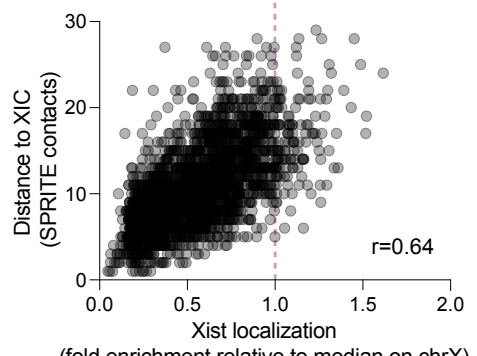

(fold enrichment relative to median on chrX)
H

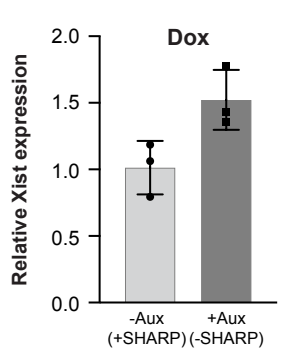

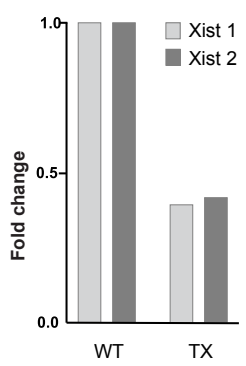

I

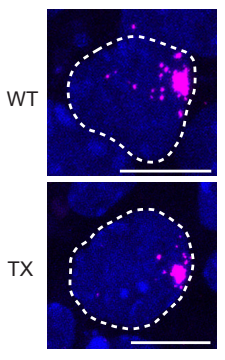

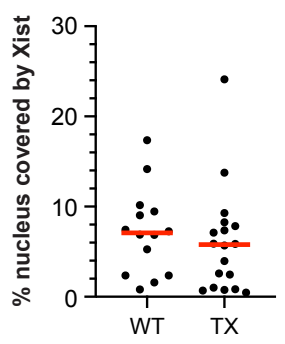

\section{Figure S5: Xist expression levels limit its ability to spread to autosomes}

(A) Top: schematic depicting expected ratios of SHARP to Xist based on increasing concentration of Xist RNA; bottom: diagrams illustrating non-stoichiometric and stoichiometric gene silencing by Xist. (B) Randomized Xist localization in simulated single cells (permutations) compared to experimental data. Top panel: Xist localization after 48 hours of RA-differentiation in female mESCs from bulk RAP-DNA experiments (16); middle panel: gene density across X, only genes that undergo XCl are plotted; bottom panel: randomized localization of 200 Xist molecules in 1000 random "cells"; Xist represented by black squares. (C) Simulation visualizing localization of Xist molecules over genes that undergo transcriptional silencing during XCl across 20 cells (zoom-in from Fig. S5B). Percent reflects proportion of Xist molecules overlapping the gene in all 1000 permutations. (D) Expression levels of Xist in several populations of cells treated with increasing dox concentrations as measured by RT-qPCR using two different primer pairs (Xist 1 and Xist 2). Samples normalized to i) RA-differentiated levels and ii) GAPDH levels. (E) Comparison of Xist occupancy (black lines; 3x dox RAP data) and DNA contact frequency with Xist locus (red lines, SPRITE data) across 1Mb DNA regions of chr8. Xist enrichment and $3 D$ distance are normalized to their median coverage across chromosome 8 to place them on the same relative scale. (F) Scatterplot representing the frequency of 3D contacts between each $1 \mathrm{Mb}$ autosomal bin with the Xist locus (SPRITE data; y axis) and DNA sites enriched by Xist when expressed at high concentration (3x dox; RAP-DNA data; x-axis). (G) Relative Xist expression upon RA-induced differentiation (left) and dox-induction (right) of female SHARP-AID mESCs in the absence or presence of auxin as measured by RT-qPCR (primer pair Xist 2). Fold change values were calculated by normalizing to the median of RA differentiated or dox-induced cells in the absence of auxin. Individual points show each replicate value. (H) Relative Xist expression in RA differentiated wildtype cells that do not contain dox-inducible Xist (left) and TX cells with dox-induced Xist (right) as measured by RT-qPCR (primer pairs Xist 1, 2). Fold change values were calculated by normalizing to the median of RA differentiated or dox-induced cells in the absence of auxin. Individual points show each replicate value. (I) Left: Images of Xist territories in wildtype cells and TX cells; right: \% nucleus occupied by Xist in the same cell lines as measured by FISH (Xist) and DAPI (nucleus). 


\title{
MATERIALS AND METHODS
}

\section{CELL CULTURE, CELL TREATMENTS, AND CELL LINE GENERATION}

\author{
Mouse ES cell culture
}

Wildtype and endogenous SHARP-HALO-AID TX1072 female mouse embryonic stem cells (mESCs; gift from E. Heard lab) were cultured as previously described [24,39]. Briefly, TX1072 mESCs were grown on gelatin-coated plates in serum-containing ES cell medium (high glucose DMEM (Gibco, Life Technologies), 15\% FBS (Omega Scientific), $2 \mathrm{mM}$ L-glutamine (Gibco, Life Technologies), $1 \mathrm{mM}$ sodium pyruvate (Gibco, Life Technologies), $0.1 \mathrm{mM}$ $\beta$-mercaptoethanol, $1000 \mathrm{U} / \mathrm{ml}$ leukemia inhibitory factor (LIF, Chemicon)), and 2i (3 $\mu \mathrm{M}$ Gsk3 inhibitor CT-99021, $1 \mu \mathrm{M}$ MEK inhibitor PD0325901). Cell culture medium was replaced every 24 hours.

Expression of Xist and/or each SHARP rescue construct (FL-SHARP, $\triangle R R M-S H A R P, \triangle I D R-S H A R P$, FUS- $\triangle$ IDRSHARP; see Table 1 for complete plasmid list) was induced by treating cells with $2 \mu \mathrm{g} / \mathrm{mL}$ doxycycline (Sigma) for at least 72 hours. Doxycycline-containing medium was replaced every 24 hours. For experiments using SHARP-AID mESCs, cells were treated with indole-3-acetic acid (IAA) for 24 hours before the addition of doxycycline to ensure complete degradation of endogenous SHARP prior to induction of Xist and SHARP rescue constructs. For RNA FISH and immunofluorescence, cells were trypsinized into a single cell suspension, plated directly on poly-D-lysine coated coverslips, and grown for at least six hours before fixation.

\section{Human HEK293T cell culture}

HEK293T cells were cultured in complete media comprised of DMEM (Gibco, Life Technologies) supplemented with $10 \%$ fetal bovine serum (Seradigm Premium Grade HI FBS, VWR), 1X penicillin-streptomycin (Gibco, Life Technologies), 1mM sodium pyruvate (Gibco, Life Technologies), and 1X MEM non-essential amino acids (Gibco, Life Technologies). Cells were maintained in 37oC incubators under 5\% CO2.

\section{Differentiation with retinoic acid}

Wildtype (F1) and TX1072 female mESCs were grown for 24 hours in ES cell medium. ES cell medium was then replaced with MEF medium (high glucose DMEM (Gibco, Life Technologies), 10\% FBS (Omega Scientific), 2mM L-glutamine (Gibco, Life Technologies), $1 \mathrm{mM}$ sodium pyruvate (Gibco, Life Technologies), 0.1mM MEM non-essential amino acids (Gibco, Life Technologies), $0.1 \mathrm{mM} \beta$-mercaptoethanol). After 24 hours in MEF medium, the medium was replaced with MEF medium supplemented with $1 \mu \mathrm{M}$ retinoic acid (RA; Sigma). Cells were then grown in MEF medium containing RA for 24 hours (48 hours differentiation total) or 48 hours (72 hours differentiation total). For cells differentiated for 72 hours, MEF medium containing RA was replaced after 24 hours.

To ensure that replacement of the endogenous Xist promoter with a doxycycline-inducible promoter in TX1072 cells does not impair endogenous expression of Xist upon differentiation, Xist levels were measured in both TX1072 and F1 female mESCs (using RT-qPCR; protocol and quantification described below) after 72 hours of differentiation with retinoic acid. Based on this bulk measurement, Xist levels in TX1072 mESCs were approximately half of those in F1 mESCs (Fig. S5H); however, the percent of single cell nuclei occupied by Xist in both TX1072 and F1 mESCs was roughly the same (Fig. S5I; protocol and quantification described below).

\section{SHARP-KO cell line generation}

To generate a plasmid targeting SHARP for deletion (see Table 1 for complete plasmid list), four different gRNA sequences (see Table 2 for sequences; Fig. S3A) were multiplexed into a Cas9-nickase backbone (Addgene plasmid 48140) as previously described [64]. To create a SHARP knockout (SHARP-KO) cell line, two million TX1072 mESCs were transfected with $1.25 \mu \mathrm{g}$ of the multiplexed Cas9n-gRNA plasmid containing GFP using the Neon transfection system (settings: $1400 \mathrm{~V}, 10 \mathrm{~ms}$ width, 3 pulses). Successfully transfected cells were enriched by performing FACS for GFP and subsequently plated at low-confluency. After 4-5 days of growth, 96 single colonies were picked and seeded in a 96-well plate. These cells were then split into one plate for PCR genotyping and another plate for maintaining growth until positive clones were identified. PCR genotyping was performed using Q5 High-Fidelity 2X Master Mix (NEB) with the primer pairs listed in Table 2. SHARP-KO clone H8 was used for subsequent experimentation and all other clones were frozen. 


\section{SHARP rescue lines in SHARP-KO or SHARP-AID parent cells}

To generate SHARP rescue cell lines, SHARP rescue constructs (FL-SHARP, $\triangle$ RRM-SHARP, $\triangle$ IDR-SHARP, FUS- $\triangle$ IDR-SHARP; Fig. S3B; see Table 1 for complete plasmid list) were first made using the Gateway LR Clonase system (ThermoFisher). Specifically, $\triangle R R M-S H A R P$ and $\triangle I D R-S H A R P$ entry clones were created by modifying a full-length mouse SHARP entry clone using polymerase incomplete primer extension (PIPE) mutagenesis [65]. The specific amino acids deleted in the $\triangle$ RRM-SHARP and $\triangle I D R-S H A R P$ entry clones are as follows.

$\triangle$ RRM-SHARP: amino acids 2-590

$\triangle$ IDR-SHARP: amino acids 639-3460

These entry clones (FL-SHARP, $\triangle$ RRM-SHARP, $\triangle$ IDR-SHARP) were then recombined into two different modified versions of the doxycycline inducible PiggyBac destination vector PB-TAG-ERN (Addgene plasmid 80476) containing NGFR (truncated human nerve growth factor receptor) and HALO or eGFP. This destination vector was chosen as it enables stable integration of the rescue constructs by co-transfecting with a PiggyBac transposase [66]. The HALO-tagged version of this plasmid was created by replacing eGFP with NGFR (Addgene plasmid 27489) using Gibson assembly (NEB). HALO was then introduced downstream of rtTA using restriction enzyme digestion and ligation to create PB-HALO-IRES-NGFR. To generate the eGFP-tagged version of this plasmid, HALO was replaced with a 6-HIS-TEV-eGFP sequence using restriction enzyme digestion and ligation. Importantly, eGFP in this construct contains an amino acid substitution (A206K) in order to create a monomeric variant [67].

FUS- $\triangle I D R-S H A R P$ was generated by recombining the $\triangle I D R-S H A R P$ entry clone into a modified version of the PB-HALO-IRES-NGFR vector containing the IDR sequence from the FUS protein tagged with mCherry (Addgene plasmid 101223) in place of HALO. Importantly, the IDR from FUS exhibits no sequence homology to endogenous SHARP IDRs (i.e. they have distinct amino acid compositions and distinct proportions of amino acid charge properties), its sequence is $\sim 10$-fold shorter that SHARP IDRs, and the locations of these two IDRs within the SHARP protein are distinct (Fig. S3B).

To generate mESC lines expressing these SHARP rescue constructs, two million SHARP-KO clone H8 or SHARP-AID mESCs were transfected with $2.4 \mu \mathrm{g}$ of the respective SHARP rescue construct tagged with HALO or eGFP (Table 1), along with $0.8 \mu \mathrm{g}$ of PiggyBac transposase plasmid (gift from M. Elowitz lab) and $1.2 \mu \mathrm{g}$ of a non-targeting GFP plasmid (turboGFP; Addgene plasmid 69072 cloned into pcDNA backbone with CMV promoter). Cells that were successfully transfected with the plasmids of interest (SHARP rescue constructs in HALO- or eGFP-tagged PiggyBac destination vector and PiggyBac transposase) were enriched by performing FACS on the co-transfected, non-targeting GFP. Cells were then cultured for 4-5 days to enable the SHARP rescue constructs to stably integrate into the genome (without inducing expression of Xist or the SHARP rescue proteins).

Next, cells were treated with IAA (for SHARP-AID mESCs) and doxycycline (previously described) to induce expression of Xist and the SHARP rescue proteins. Importantly, these cells were cultured in doxycycline for a minimum of 72 hours to ensure that any cells with toxic SHARP expression levels did not survive and were not analyzed further. For HALO-tagged rescue constructs, cells were labeled with $1 \mu \mathrm{M}$ HaloTag Oregon Green Ligand (Promega) according to the manufacturer's instructions and both the HALO- and eGFP-tagged cell lines were sorted again to enrich for cells expressing the HALO- or eGFP-tagged SHARP rescue constructs (Fig. S3C).

During FACS, laser powers and gains were set based on the lowest expressing samples (FL-SHARP) and these settings were used for all other samples to enrich for cells with comparable expression levels of each rescue construct. Following FACS, cells were kept in medium supplemented with doxycycline and used in further experiments (CLAP, IF, RNA-FISH). Cells were retained only for a maximum of 14 days of culture in doxycycline.

\section{Overexpression of SHARP rescue constructs in HEK293T}

For those experiments that required high protein expression (live-cell imaging, concentration-dependent imaging assays, CLAP, FRAP), human HEK293T cells were used instead of mESCs because they allow for much higher expression levels and enabled investigation of the biochemical and biophysical properties of each SHARP rescue construct in an independent system that is not undergoing initiation of $\mathrm{XCl}$.

HEK293T cells were transfected using BioT transfection reagent (Bioland) according to manufacturer's recommendations. Transfected constructs include FL-SHARP, $\triangle R R M-S H A R P, \triangle I D R-S H A R P$, FUS- $\triangle I D R-S H A R P$, EED, Ptbp1, or an empty backbone (Table 1); all constructs contained eGFP attached to the N-terminus of each protein of interest driven by a doxycycline-inducible promoter.

For live-cell imaging, fixed imaging, and FRAP (Fig. 2; Fig. S2) 10 $\mu$ g of DNA was used for transfection when cells 
were grown on a $15 \mathrm{~cm}$ dish or $\sim 1 \mathrm{ug}$ of DNA when cells were grown on $3 \mathrm{~cm}$ glass-bottom dishes (Matek), and DNA concentrations were adjusted to match mole numbers across constructs. 24 hours after transfection, cells were treated with doxycycline $(2 \mu \mathrm{g} / \mathrm{mL}$ doxycycline (Sigma)) to induce expression of the proteins of interest and further experiments were performed 48 hours post-doxycycline treatment.

For assays measuring concentration-dependent assembly formation (Fig. 2D, 2E), 2.5 fmol of DNA was transfected per well of 24-well plate, adjusting DNA concentration based on the construct being used. 24 hours after transfection, cells were treated with increasing concentrations of dox $(0 x, 0.1 \mathrm{x}, 0.5 \mathrm{x}, 1 \mathrm{x}$ where $1 \mathrm{x}=2 \mu \mathrm{g} / \mathrm{mL})$ for 24 hours.

\section{PROTEIN AND RNA VISUALIZATION}

\section{Single molecule RNA fluorescence in situ (smRNA-FISH)}

RNA-FISH experiments were performed using the ViewRNA ISH Cell Assay (ThermoFisher, QVC0001) protocol with minor modifications. Specifically, cells were fixed on coverslips with $4 \%$ formaldehyde in PBS for 15 minutes at room temperature and then permeabilized with $4 \%$ formaldehyde and $0.5 \%$ Triton X-100 in PBS for 10 minutes at room temperature. Cells were then washed twice with PBS, dehydrated with $70 \%$ ethanol, and incubated at $-20 \circ \mathrm{C}$ for at least 20 minutes or stored for up to one week. Coverslips were washed twice with PBS and then incubated with the desired combination of RNA FISH probes (Fig. S4A; Table 3; Affymetrix) in Probe Set Diluent at $40 \circ \mathrm{C}$ for at least three hours. Coverslips were then washed once with Wash Buffer, twice with PBS, and once more with Wash Buffer before incubating in PreAmplifier Mix Solution at $40 \circ \mathrm{C}$ for 45 minutes. This step was repeated for the Amplifier Mix Solution and Label Probe Solution. Coverslips were incubated with 1X DAPI in PBS at room temperature for 15 minutes and subsequently mounted onto glass slides using ProLong Gold with DAPI (Invitrogen, P36935).

\section{Immunofluorescence (IF)}

To focus our analysis specifically on nuclear SHARP, pre-extraction was performed on cells prior to immunostaining as previously described [61]. In brief, cells on coverslips were washed once with PBS and then incubated with cold $0.1 \%$ Triton X-100 in PBS for 1-3 minutes on ice. Next, cells were fixed on coverslips with $4 \%$ formaldehyde in PBS for 15 minutes at room temperature and permeabilized with $0.5 \%$ Triton X-100 in PBS for 10 minutes at room temperature. After washing two times with PBS containing $0.05 \%$ Tween (PBSt) and blocking with 2\% BSA in PBSt for 30 minutes, cells were incubated with primary antibodies overnight at $40 \mathrm{C}$ in $1 \%$ BSA in PBSt. After overnight incubation at $4 \mathrm{oC}$, cells were washed 3 times in $1 \mathrm{x}$ PBSt and incubated for 1 hour at room temperature with secondary antibodies labeled with Alexa fluorophores (Invitrogen) diluted in 1x PBSt (1:500). Next, coverslips were washed three times in PBSt, rinsed in PBS, rinsed in ddH2O, mounted with ProLong Gold with DAPI (Invitrogen, P36935), and stored at 4oC until acquisition.

Primary antibodies and the dilutions used are as follows: anti-Halo (mouse, Promega G9211, 1:200); anti-Ezh2 (mouse, Cell signaling AC22 3147S, 1:500); anti-SHARP (rabbit, Bethyl A301-119A, 1:200).

\section{RNA-FISH \& Immunofluorescence}

For IF combined with in situ RNA visualization, the ViewRNA Cell Plus (Thermo Fisher Scientific, 88-19000-99) kit was used according to the manufacturer's protocol with minor modifications. First, immunostaining was performed as described above but all incubations were performed in blocking buffer containing RNAse inhibitor from the kit and all wash steps were done in RNAse-free PBS with RNAse inhibitor. Blocking buffer, PBS, and RNAse inhibitors were provided with the kit. After the last wash in PBS, cells underwent post-fixation with $2 \%$ formaldehyde in PBS for 10 minutes at room temperature, were washed 3 times in PBS, and then RNA-FISH was performed as described above.

\section{HALO tag staining}

To visualize proteins expressing HALO tags, HaloTag TMR (G8252) or OregonGreen (G2802) was used for fixed sample imaging combined with IF (Fig. S3D) and Janelia549 (GA1110) was used for combined HALO staining and RNA-FISH visualization (Fig. 1B; Fig. S1G). Janelia549 was used for combined HALO staining and RNA-FISH visualization because other HALO ligands did not survive the RNA-FISH protocol. For protein labeling, cells were 
incubated with HaloTag Ligands according to manufacturer's instructions and then directly imaged or washed with PBS, fixed in $4 \%$ formaldehyde (Pierce, ThermoFisher Scientific), and combined with immunostaining or RNA-FISH.

\section{IMAGE ACQUISITION AND ANALYSIS}

\section{Microscopy}

Fixed samples were imaged using: Zeiss LSM 800 with the 63x oil objective (RNA-FISH, IF) and collected every 0.3um for 16 Z-stacks, Zeiss LSM 880 with Airyscan with the $63 x$ oil objective (IF) and collected every 0.25 um for 20 Z-stacks, or Zeiss LSM 980 with Airyscan2 with the 63x oil objective (IF, RNA-FISH-IF) where zoom, scan format, and number of Z-stacks were optimized based on the software recommendations for the highest resolution (Super-Resolution module). For all images, laser power and gain were set at the beginning of acquisition and remained constant throughout the duration of acquisition to enable comparisons of fluorescent intensities. Live samples were imaged using the Leica Stellaris microscope with $63 x$ water objective ( 80nm xy, $\sim 300 \mathrm{~nm} z)$, and 16 Z-stacks were collected every 60 seconds for 5 minutes. The microscope was equipped with a stage incubator to keep cells at $37^{\circ} \mathrm{C}$ and $5 \% \mathrm{CO} 2$.

\section{Image quantification}

Image analysis was performed using ICY or FIJI (ImageJ v2.1.0/1.53c) software. Live-cell movies and 3D reconstructions were created using Imaris software from Bitplane (Oxford Instruments Company).

\section{Enrichment over inactive $\mathbf{X}$ territory}

Xist and SHARP enrichments over the Xist territory (Fig. 1) were quantified using lcy (illustration Fig. S3E). First, a region-of-interest (ROI) was defined that corresponded to the Xist signal across all Z-stacks by applying an intensity threshold (signal above background) and a binary mask was created by demarcating the Xist-coated territory (ROI). Next, several features of these ROls were quantified, namely: the areas in $\mu \mathrm{m} 2$ (Area), total fluorescent intensities of Xist or SHARP over the entire ROI (Total Intensity), and average fluorescent intensity of Xist or Sharp per area unit of ROI (pixel/interior) (Average Intensity).

SHARP rescue construct enrichments over the Xi demarcated by Ezh2 staining (Fig. 3A, 3B) were quantified using Icy (illustration Fig. S3E). First, images were processed into maximum intensity projections and two types of regionof-interest were specified per each nucleus: i) corresponding to the Xi $(X)$ by creating a binary mask based on Ezh2 marker, ii) and a control region corresponding to a random region $(R)$ of the same size across all Z-stacks. Next, the average fluorescent intensities of SHARP or Ezh2 was quantified per each ROI (X or R). Finally, to normalize for intercellular differences in the expression of rescue constructs, $\mathrm{ROI}-\mathrm{R}$ was subtracted from $\mathrm{ROI}-\mathrm{X}$ and divided by $\mathrm{ROI-X}$. As such, if fluorescent intensity signal over the $\mathrm{X}$ chromosome $(X)$ is not higher that fluorescent signal in a comparably sized random region in the nucleus $(R)$, the fold change should be centered around 0 , whereas when there is enrichment, the signal should be greater than 0 .

\section{Pattern of SHARP localization}

To determine the pattern of SHARP localization after transfecting HEK293T cells with eGFP-SHARP constructs (Fig. 2E, 2G; Fig. S2A), images were first processed into a maximum intensity projection using lcy software. Then, a binary mask was created to demarcate each nucleus of a transfected cell by setting a threshold of eGFP intensity above background levels; all masks were visually verified and, if needed, manually adjusted to fit the nuclear region of cells. Based on these masks, an ROI was defined that corresponded to the entire nucleus. Values for each pixel with the ROI (nucleus) were then extracted and this extracted information was used to quantify total intensity of protein per nucleus (sum of all pixels in an ROI), which corresponds to protein expression levels, and to calculate a SHARP dispersion score describing the differences in the distribution of pixel intensities across the nucleus. Specifically, for each cell, the intensity value at the 99th percentile of the distribution was computed and divided by the mode of the intensity distribution. This score was used because diffused localization shows distributed intensity across the nucleus and non-diffused localization shows accumulation of signal in defined locations, such that the tails of the intensity distributions were much longer. These quantitative assignments were visually confirmed to ensure that these scores capture our definition of diffused and non-diffused organization across cells. 


\section{Intron RNA FISH}

For intron RNA FISH analysis, each image was processed into a maximum intensity projection using Fiji software. Then, the number of spots corresponding to each intron FISH probe per nucleus was manually counted and scored for the presence of Xist signal, number of spots per escape gene (Kdm5c, Kdm6a), and number of spots per silenced gene (Atrx, Pgk1, MeCP2, Gpc4) (Fig. 4A). Because mESCs are known to lose one of the X chromosomes or its fragments while in culture $[39,54,55]$ (Fig. S4B), the analysis was restricted to cells containing two X chromosomes, which were determined by the presence of exactly two spots from escape gene. Additionally, those cells that had more than two spots per any gene or more than one Xist territory per nucleus were excluded from the analysis.

\section{Xist percent of nucleus}

To calculate the percent of each nucleus occupied by Xist, each image was first processed into a maximum intensity projection using Fiji software. Then, a binary mask was created to demarcate each nucleus by setting a threshold intensity based on DAPI staining; all masks were visually verified and, if needed, manually adjusted to fit the nuclear region of cells. Based on these masks, an ROI was defined that corresponded to the entire nucleus and the size of the nucleus was calculated in FIJI based on the image metadata. Another binary mask was then created to demarcate the Xist territory by setting a threshold intensity based on Xist RNA-FISH staining; all Xist masks were also visually verified and manually adjusted if necessary. An ROI was defined based on these masks and the size of this territory was calculated in FIJI based on the image metadata. The percent of each nucleus occupied by Xist was calculated by dividing the area of the Xist territory by the area of the corresponding DAPI-demarcated nucleus.

\section{Fluorescence Recovery After Photobleaching (FRAP)}

FRAP experiments were performed in HEK293T cells overexpressing eGFP-tagged FL-SHARP, PTBP1, or EED. 48 hours post-transfection, cells were subjected to FRAP as previously described [68] using the Zeiss LSM 710 with the $40 \mathrm{x}$ water objective and equipped with a stage incubator to keep cells at $37^{\circ} \mathrm{C}$ and $5 \% \mathrm{CO} 2$. Briefly, in each nucleus $\sim 1 \mu \mathrm{m} 2$ area was bleached with the Argon laser to quench eGFP and fluorescence recovery was followed while imaging in the GFP channel for 235 seconds. FRAP experiments were analyzed first by measuring the mean fluorescence intensity in the bleached area over time using lcy software and then normalized and averaging over $n$ number of cells $(n>5)$ using EasyFRAP software [69]. Error bars represent standard deviation of at least 5 replicates.

\section{COVALENT LINKAGE AFFINITY PURIFICATION (CLAP) FOLLOWED BY RNA SEQUENCING}

\section{Purification of HALO-tagged SHARP}

CLAP was performed on mESCs expressing HALO-tagged SHARP constructs (Table 1) as previously described [70] (Fig. 3C, 3D). Briefly, post-transfection, media was removed from cells and then crosslinked on ice using 0.25 $\mathrm{J} \mathrm{cm-2} \mathrm{(UV2.5k)} \mathrm{of} \mathrm{UV} \mathrm{at} 254 \mathrm{~nm}$ in a Spectrolinker UV Crosslinker. Cells were collected by scraping in 1X PBS and pelleted by centrifugation. Cell pellets were resuspended in $1 \mathrm{~mL}$ of ice cold lysis buffer $(50 \mathrm{mM}$ Hepes, $\mathrm{pH}$ 7.4, $100 \mathrm{mM} \mathrm{NaCl}, 1 \%$ NP-40, 0.1\% SDS, 0.5\% Sodium Deoxycholate) supplemented with 1X Protease Inhibitor Cocktail (Promega), $200 \cup$ of Ribolock (ThermoFisher), $20 \cup$ Turbo DNase (Ambion), and 1X Manganese/Calcium Mix (0.5mM CaCl2, $2.5 \mathrm{mM} \mathrm{MnCl2).} \mathrm{The} \mathrm{samples} \mathrm{were} \mathrm{incubated} \mathrm{on} \mathrm{ice} \mathrm{for} 10$ minutes and then at $37^{\circ} \mathrm{C}$ for 10 minutes at $700 \mathrm{rpm}$ shaking on a Thermomixer (Eppendorf). Lysates were cleared by centrifugation at 15,000 $\mathrm{g}$ for 2 minutes, and the supernatant is used for capture. For Halo-protein capture $50 \mu \mathrm{L}$ of HaloLink Resin was pre-blocked using 1 X Blocking Buffer ( $50 \mathrm{mM}$ HEPES, $\mathrm{pH} 7.4,100 \mu \mathrm{g} / \mathrm{mL}$ BSA) for 20 minutes at room temperature with continuous rotation. After incubation, the resin was washed three times with 1X PBSt. The cleared lysate was mixed with 50 $\mathrm{\mu l}$ of pre-blocked HaloLink Resin and incubated at $4{ }^{\circ} \mathrm{C}$ for $3-16$ hours with continuous rotation. The captured protein bound to resin was washed three times with lysis buffer at room temperature and then washed three times at $90^{\circ} \mathrm{C}$ for 3 minutes while shaking on a Thermomixer at $1200 \mathrm{rpm}$ with each of the following buffers: 1X NLS buffer (1xPBS, 2\% NLS, 10 mM EDTA), High Salt Buffer (50 mM HEPES, pH 7.4, 0.1\% NP-40, 1M NaCl), 8M Urea Buffer (50 mM HEPES, pH 7.5, 0.1\% NP-40, 8 M Urea), Tween buffer (50 mM HEPES, pH 7.4, 0.1\% Tween 20) and TEV buffer (50 mM HEPES, pH 7.4, 1 mM EDTA, 0.1\% NP-40). Between each wash, samples were centrifuged at $1,000 \mathrm{~g}$ for 30 seconds and supernatant was removed. After the last wash, samples were centrifuged at $7,500 \mathrm{~g}$ for 30 seconds and supernatant was discarded. For elution, the resin was resuspended in $100 \mu \mathrm{L}$ of NLS Buffer and $10 \mu \mathrm{L}$ of Proteinase K (NEB) and the sample was incubated at $50^{\circ} \mathrm{C}$ for 30 minutes while 
shaking at $1200 \mathrm{rpm}$. Capture reactions were transferred to microspin cups (Pierce, ThermoFisher), centrifuged at 2,000 $\mathrm{g}$ for 30 seconds, and the elutions were used for RNA purification by RNA Clean and Concentrate- 5 kits (Zymo, >17nt protocol).

\section{RNA library preparation and sequencing}

RNA-seq library preparation was carried out as previously described [71]. Briefly, purified RNA was dephosphorylated (Fast AP) and cyclic phosphates were removed (T4 PNK). The RNA was then cleaned using Silane beads. An RNA adaptor containing a reverse transcription (RT) primer binding site was ligated to the 3' end of the RNA and the ligated RNA was reverse transcribed into CDNA. The RNA was then degraded using $\mathrm{NaOH}$ and a second adaptor was ligated to the single-stranded cDNA. The DNA was amplified, and Illumina sequencing adaptors were added by performing PCR with primers that are complementary to the 3' and 5' adapters that were previously added. The molarity of each PCR amplified library was measured using an Agilent Tapestation High Sensitivity DNA screentape and the samples were then pooled at equal molarity. This library pool was then size selected on a $2 \%$ agarose gel by cutting between 150-800 nucleotides and performing gel purification (Zymo). To determine the loading density of the final pooled library, the sample was measured using an Agilent Bioanalyzer and Qubit dsDNA High Sensitivity assay (ThermoFisher). The final library was paired-end sequenced on an Illumina HiSeq 2500 with read length $35 \times 35$ nucleotides.

\section{CLAP analysis and visualization}

For HALO purifications and RNA binding mapping, sequencing reads were aligned to the mouse genome (RefSeq mm10) using STAR aligner. All low-quality alignments (MAPQ < 255) and PCR duplicates were excluded from the analysis using the Picard MarkDuplicates function (https://broadinstitute.github.io/picard/). The enrichment relative to input coverage across the Xist RNA was quantified by computing the number of reads overlapping the window in the SHARP-elution sample divided by the total number of reads within the SHARP-elution sample. This ratio was normalized by dividing the number of reads in the same window contained in input sample by the total number of reads in the input sample. Because all windows overlapping a gene should have the same expression level in the input sample (which represents RNA expression), the number of reads in the input was estimated as the maximum of either (i) the number of reads over the window or (ii) the median read count over all windows within the gene. This approach provides a conservative estimate of enrichment because it prevents windows from being scored as enriched if the input values over a given window are artificially low, while at the same time accounting for any non-random issues that lead to increases in read counts over a given window (e.g. fragmentation biases or alignment artifacts leading to non-random assignment or pileups). These enrichment values were visualized in IGV [72].

\section{Crosslink induced truncation sites}

Because UV-crosslinking forms an irreversible covalent crosslink, reverse transcriptase has a well-described tendency to stall at crosslink sites. To exploit this information to identify information about putative protein binding sites at nucleotide resolution, the second adaptor is ligated to the 3' end of the cDNA. In this way, the start position of the second read in a sequencing pair corresponds to this CDNA truncation point. To quantify these positions, the frequency of reads that start at each nucleotide was counted and plotted along the Xist RNA to identify the positions of direct crosslinking between the protein of interest and the RNA.

\section{RNA AFFINITY PURIFICATION (RAP) FOLLOWED BY DNA SEQUENCING}

\section{Cell treatment and preparation}

For RAP-DNA sequencing, TX1072 cells were treated with increasing dox concentrations $(0.25 \mathrm{x}, 0.5 \mathrm{x}, 1 \mathrm{x}, 2 \mathrm{x}, 3 \mathrm{x}$ where $0 x=$ no dox and $1 \mathrm{x}=2 \mu \mathrm{g} / \mathrm{ml}$ ) for 72 hours, changing dox containing medium daily. Cells were harvested and crosslinked as previously described [56]. Briefly cells were pelleted, crosslinked with $2 \mathrm{mM}$ disuccinimidyl glutarate for 45 minutes and 3\% formaldehyde for 10 minutes, and lysed. Chromatin was then digested to 100-500 bp fragments through a combination of sonication and treatment with TURBO DNase and cell lysates were stored at $-800 \mathrm{C}$ until the next step of the procedure. 


\section{Purification of DNA sites bound by Xist RNA}

DNA fragments occupied by Xist RNA were purified for RAP-DNA as previously described [16] with minor modifications. Briefly, the lysate was diluted to hybridization conditions containing $3 \mathrm{M}$ guanidine thiocyanate, precleared by adding streptavidin-coated magnetic beads and incubating for 30 minutes at $37^{\circ} \mathrm{C}$, mixed with biotin-labeled single stranded DNA capture probes, and incubated at $37^{\circ} \mathrm{C}$ for 2 hours. 90 -mer single stranded DNA oligonucleotide probes spanning the entire length of the target Xist RNA were purchased containing a 5' biotin (Eurofins Operon) [22]. Next, captured chromatin complexes were eluted with RNaseH and crosslinks were reversed by adding Proteinase $\mathrm{K}$ to the probe-bead complexes and incubating overnight at $65^{\circ} \mathrm{C}$. Standard Illumina sequencing libraries were generated from eluted DNA fragments and sequenced at a depth of 5-20 million reads per sample of 75-75 or 75-140 long paired-end reads per sample.

\section{RAP-DNA analysis and visualization}

$X$ to Autosome enrichments were calculated by counting the number of reads that aligned to the $X$ and the number aligned to autosomes (A). This proportion was then compared to the proportion of reads that align to the $\mathrm{X}$ or $\mathrm{A}$ in the total input sample, which represent the total genomic DNA coverage without any selection. To compute enrichments per region of the genome, the number of reads for each genomic region within 10 kilobase windows was counted and this count was normalized by the total number of sequencing reads within each sample. Each window was then normalized by the proportion measured in the same bin within the input samples. To explore regions on autosomes that contain high Xist coverage, each bin was divided by the median values present on the $\mathrm{X}$ chromosome. In this way, all genomic regions containing coverage that was at least as high as half of the regions on the $\mathrm{X}$ chromosome could be visualized and their enrichment levels could be directly compared to the overall $\mathrm{X}$ chromosome coverage.

\section{Computing 3D contact frequencies with the Xist locus}

$3 \mathrm{D}$ contact frequency between individual genomic regions and the Xist transcription locus was calculated as previously described [56]. Specifically, all SPRITE clusters containing a DNA read overlapping the Xist locus (chrX:103460373-103483233, mm10) were extracted and a genome-weight contact frequency was computed by counting the total number of SPRITE clusters for each genomic region within this set. The analysis exclusively focused on clusters containing 2-100 reads per cluster and weighted the contact frequency by the cluster size from which it was present (2/cluster size) as previously described.

\section{RT-qPCR}

Dox-induced and differentiated female mESCs were lysed in RLT (Qiagen) containing $\beta$-mercaptoethanol at a 1:100 dilution. RNA was then isolated using the RNeasy Mini Kit (Qiagen) according to the manufacturer's instructions. Genomic DNA was removed from the purified RNA samples with TURBO DNase (ThermoFisher) per the manufacturer's protocol. Total RNA was then purified again using the RNA Clean and Concentrate-5 kit (Zymo, $>17$ nt protocol). cDNA was generated from purified RNA using Maxima $\mathrm{H}$ minus reverse transcriptase (ThermoFisher) with random 9mers according to manufacturer's specifications.

Amplification reactions were run in a Roche LightCycler 480 instrument using LightCycler 480 SYBR Green I Master (Roche) with the primer pairs listed in Table 2. Each sample had between one and six biological replicates and four technical replicates. Median Ct values were used to calculate fold change with the 2- $\Delta \Delta \mathrm{Ct}$ method. For differentiation and dox induction conditions in the presence or absence of auxin (Fig. 5I), each biological replicate was normalized to the median of the corresponding "with SHARP (-Aux)" condition. For dox-induced samples across increasing concentrations (Fig. S5D), each sample was normalized to the corresponding differentiation (RA) sample. For differentiated wildtype (F1) and TX1072 mESCs (Fig. S5H), each sample was normalized to the corresponding wildtype sample.

\section{Other data used in this study:}

RAP-DNA ( $F 12-1+48$ hours of RA): Xist localization across the $X$ chromosome relative to gene density was measured using our previously published RAP-DNA dataset generated from Xist purification in F1 female mESCs differentiated with retinoic acid for 48 hours [16]. All normalizations and analyses were performed as previously described and plotted using the normalized bedgraphs available at GEO accession GSE46918.

SPRITE (F1 2-1 mESCs): 3D contacts were measured using our previously published RNA-DNA SPRITE dataset 
bioRxiv preprint doi: https://doi.org/10.1101/2021.10.27.466149; this version posted October 28, 2021. The copyright holder for this preprint (which was not certified by peer review) is the author/funder, who has granted bioRxiv a license to display the preprint in perpetuity. It is made available under aCC-BY-NC-ND 4.0 International license.

[61] that was generated in F1 female mESCs available at GEO accession GSE151515.

\section{Data visualization}

Bar graphs and violin plots were generated using GraphPad Prism (v8.4.3) or R (v4.0.3). Sequencing data was visualized using IGV (v2.8.11).

\section{Statistical tests}

To compare distribution of expressed alleles among two populations (Fig. 4) we used two proportions Z-test. 